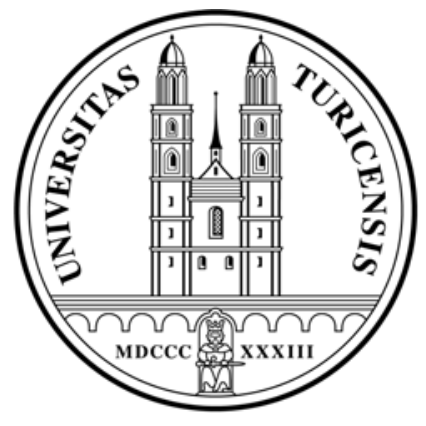

Institute for Empirical Research in Economics

University of Zurich

Working Paper Series

ISSN 1424-0459

Working Paper No. 404

\title{
Real Exchange Rates and Real Interest Rate Differentials: a Present Value Interpretation
}

Mathias Hoffmann and Ronald MacDonald

February 2009 


\title{
Real Exchange Rates and Real Interest Rate Differentials: a Present Value Interpretation ${ }^{1}$
}

\author{
Mathias Hoffmann \\ University of Zurich \\ Institute for Empirical Research in Economics \\ Zuerichbergstrasse 14, CH-8032 Zurich. \\ E-mail: mathias.hoffmann@iew.uzh.ch \\ Ronald MacDonald \\ Dept. of Economics, University of Glasgow, \\ Glasgow G12 8RT, UK \\ E-Mail: r.macdonald@lbss.gla.ac.uk
}

February 2, 2009

\footnotetext{
${ }^{1}$ The authors are grateful to the editor, Jürgen von Hagen, and to two anonymous referees for their helpful comments on an earlier draft of this paper. Hoffmann's research on this paper is part of the project The International Allocation of Risk funded by Deutsche Forschungsgemeinschaft in the framework of SFB 475 and of the MacroFinance project in the framework of University of Zurich's research priority program in Finance and Financial Markets.
} 


\begin{abstract}
Although the real exchange rate - real interest rate (RERI) relationship is central to most open economy macroeconomic models, empirical support for the relationship is generally found to be rather weak. In this paper we re-investigate the RERI relationship using bilateral U.S. real exchange rate data spanning the period 1978 to 2007. Instead of testing one particular model, we build on Campbell and Shiller (1987) to propose a metric of the economic significance of the relationship. Our empirical results provide robust evidence that the RERI link is economically significant and that the real interest rate differential is a reasonable approximation of the expected rate of depreciation over longer horizons.
\end{abstract}

JEL Classification: E43; F31; F41

Keywords: Real Exchange Rates; Real Interest Rates; Present Value Model. 


\section{Introduction}

Many well-known exchange rate models highlight the role of the real interest rate differential as a key determinant of real exchange rates. For example, sticky price models (see Dornbusch (1976) and Mussa (1984)) and optimising models (see, for example, Grilli and Roubini (1992) and Obstfeld and Rogoff (1996)) emphasize the effect of liquidity impulses on real interest rates and consequently the real exchange rate. This relationship is often summarised in the form of the real exchange rate - real interest rate (RERI) relationship.

However, despite its centrality to many open economy macro models, the empirical evidence on the RERI relationship is rather mixed. In this paper we revisit the RERI relationship and suggest a new way of testing it, based on the VAR-method of Campbell and Shiller (1987) for testing present value models. Our results indicate that the real interest rate differential is a reasonable proxy for the expected real depreciation of the US dollar and can be interpreted as the transitory part of the real exchange rate. This empirical finding provides strong support for the results of Baxter (1994) and also of Edison and Pauls (1993) who have emphasized that the link between real exchange rates and real interest differentials is to be found in the business cycle domain, instead of lower frequencies.

Our way of casting the RERI relationship into an empirical model rests on the idea that the real interest rate differential is the sum of expected period-to-period changes in real exchange rates. In this context, the real interest rate differential can be interpreted as the spread variable in a present value model in which the discount factor is known and equal to one. ${ }^{1}$ This allows us to take the projection for the change in the real exchange rate

\footnotetext{
${ }^{1}$ See Engel and West (2004) for a discussion of the implications of a unitary discount rate in a present value variant of the monetary exchange rate model.
} 
from a bivariate VAR, consisting of the change in the real exchange rate and the real interest differential, and correlating this with the real interest differential. We argue that this kind of test is much closer in spirit to the RERI relationship than many extant tests and it produces measures of longrun expected changes in the exchange rate which are highly correlated with real interest rate differentials.

In our analysis we study bilateral real exchange rates for the United States vis-à-vis the other G7 countries: Canada, France, Germany, Italy, Japan and the United Kingdom. The sample period is 1978 quarter 2 to 2007 quarter 3. In common with most other applications of the VAR-based present value approach, we find that the cross-equation restrictions of the present-value model are statistically rejected. However, we note that this can be attributed to the time variability of the discount factor, rather than to a rejection of the RERI per se. Indeed, we suggest interpreting the RERI more broadly as a significant and positive relationship between expected real exchange rate changes and the real interest rate differential. We first present graphical evidence which indicates that this broader version of the RERI is strongly supported by the data and economically significant. A key aspect of our broader interpretation is that it does not amount to a test of a particular model but that it provides a taxonomy of the economic significance of the RERI by asking what fraction of the variability in interest rate differentials is explained by changes in the rate of expected depreciation. This fraction is high and significant for all pairs of exchange rates we consider. Our method can be thought of as a formalization of the approach advocated by Campbell (1986) who argued in the context of the permanent income hypothesis that '[...]models which are strongly rejected statistically may be good approximations of the behavior of economic variables' (p.29) 
We further illustrate the empirical relevance of the RERI by investigating how various structural shocks affect the relationship. While doing so sheds light on the RERI as a conditional relationship, we also view this as a way to collect a set of stylized facts on the dynamic interaction between real interest rates and real exchange rates that may also be of more general interest: under the null of the RERI, shocks to the real interest rate differential should only have a transitory impact on the real exchange rate, whereas shocks that do not affect the real interest rate differential should be associated with the permanent component. We find that these hypothesised relationships are in fact in the data. Furthermore, we also find that a positive interest rate shock leads to a temporary decline (appreciation) in the real exchange rate that is then gradually offset as relative prices and nominal interest rates adjust. This, again, is very much in line with theoretical predictions. We examine the robustness of this conclusion using an adaptation of the method suggested by King and Watson (1997), which involves examining the robustness of the response of the two variables to the choice of identification scheme. Interestingly, it turns out that our structural conclusions are independent of the particular approach to identification that we choose: the same pattern arises based on long-run identification schemes in the spirit of Blanchard and Quah (1989), more conventional short-run Choleski decompositions and, in fact, based on most other possible identifications.

The outline of the remainder of this paper is as follows. In the next section we consider the RERI relationship in some detail and discuss how the VAR-based method of Campbell and Shiller (1987) can be adapted to explore the RERI link. We then go on to outline how the relationship can be identified using the projections from a simple VAR model. In section 3 we present our empirical results, while in section 4 we examine the impact of 
structural shocks on the long-run relationship between real exchange rates and the real interest differential. Section 5 provides a further discussion of our results and concludes.

\section{The RERI as a present value relationship}

The standard derivation of the RERI (see, for example, Meese and Rogoff (1988)) has as its starting point the familiar risk adjusted uncovered interest parity condition:

$$
\mathbf{E}_{t}\left(s_{t+1}-s_{t}\right)=\left(i_{t}-i_{t}^{*}\right)+\sigma_{t},
$$

where $s_{t}$ is the log of the spot exchange rate (home currency price of a unit of foreign exchange), $i_{t}$ is the one period domestic interest rate, $\mathbf{E}_{t}$ is the conditional expectations operator, an asterisk denotes a foreign magnitude and $\sigma_{t}$ is a stationary (time-varying) risk premium. The latter term is often alternatively referred to as an excess return and we shall consider it in more detail below. Assuming rational expectations, equation (1) may be rewritten as:

$$
s_{t+1}-s_{t}=\left(i_{t}-i_{t}^{*}\right)+\sigma_{t}+\epsilon_{t},
$$

where is $\epsilon_{t}$ is an iid random error.

The nominal exchange rate is usually thought of as an I(1) process and it therefore follows that the left hand side variable in $(2), s_{t+1}-s_{t}$, must be $\mathrm{I}(0)$. Since $\sigma_{t}+\epsilon_{t}$ is stationary, by assumption, it follows that the interest differential, $i_{t}-i_{t}^{*}$, must also be stationary - the domestic interest rate must be cointegrated with the foreign interest rate. The balanced nature of this expression, in terms of the orders of integration, is a standard feature of arbitrage conditions and is the starting point of the cointegration testing methods first proposed by Campbell and Shiller (1987) for present value 
models. It turns out that translating (2) into the equivalent real interest parity condition produces a similar balance in terms of the integratedness of the right and left hand side variables. For example, by subtracting the expected inflation differential, $\mathbf{E}_{t}\left(p_{t+1}-p_{t}\right)-\mathbf{E}_{t}\left(p_{t+1}^{*}-p_{t}^{*}\right)$, from both sides of (2), where $p_{t}$ denotes the $\log$ of the domestic price level, and assuming rational expectations the following expression may be obtained:

$$
q_{t+1}-q_{t}=\left(r_{t}-r_{t}^{*}\right)+\sigma_{t}+\epsilon_{t+1}+u_{t+1}
$$

where $q_{t}=s_{t}+p_{t}^{*}-p_{t}, r_{t}$ denotes the domestic real interest rate, defined as $r_{t}=i_{t}-\mathbf{E}_{t}\left(p_{t+1}-p_{t}\right)$, and $u_{t+1}$ is an iid inflation forecast error. Since the two disturbance terms $-\epsilon_{t+1}$ and $u_{t+1}$ - and the excess-return (or risk premium) are stationary, it must follow, as in equation (2), that $q_{t+1}-q_{t}$ and $r_{t}-r_{t}^{*}$ are integrated of the same order. Since the real exchange rate is usually thought to be $\mathrm{I}(1)$, or close to $\mathrm{I}(1), q_{t+1}-q_{t}$ must be $\mathrm{I}(0)$ and therefore so too must $r_{t}-r_{t}^{*}$. However, it follows from this that $q_{t}$ and $r_{t}-r_{t}^{*}$ cannot be cointegrated (see Baxter (1994)), an issue that we discuss in more detail below.

On using the UIP condition at horizon $k-\mathbf{E}_{t}\left(s_{t+k}-s_{t}\right)=\left(i_{t}(k)-i_{t}^{*}(k)\right)-$ where $i_{t}(k)$ represents the nominal interest rates at time $t$ on $k$-period bonds and on subtracting expected $k$-horizon relative inflation rates we obtain the $k$-period version of the real interest parity relationship, (3), as:

$$
\mathbf{E}\left(q_{t+k}-q_{t}\right)=r_{t}(k)-r_{t}^{*}(k)
$$

where $r_{t}(k)=i_{t}(k)-\mathbf{E}_{t}\left(p_{t+k}-p_{t}\right)$ and we have suppressed the risk premium.

Expression (4) is the standard formulation of the RERI. We call this the strict version of the relationship and it is worth emphasizing because 
it indicates that the current real interest rate differential contains sufficient information for forecasting the expected long-run change in the real exchange rate. Hence, while an econometrician may not have access to the information set used by economic agents to form expectations, equation (4) states that current real interest differentials embody all of that information. This is a familiar insight that was first proposed by Campbell and Shiller (1987) in the context of present value models, but has not, to our knowledge, been used in the literature on the RERI relation. In particular, equation (4) indicates that past levels of the real interest rate differential should be included in the forecasting equation for real exchange rate changes. To obtain such a forecasting equation, we rewrite the expected long-run change in $q$ as the sum of period-to-period changes:

$$
\mathbf{E}_{t}\left[q_{t+k}-q_{t}\right]=\sum_{l=1}^{k} \mathbf{E}_{t}\left(\Delta q_{t+l}\right) .
$$

A straightforward way to proxy the expectations in equation (5) is to use a forecast from a VAR that includes past levels of the real interest rate differential. We illustrate this in the context of a bi-variate $\operatorname{VAR}(1)$ of the form: ${ }^{2}$

$$
\mathbf{z}_{t}=\Gamma \mathbf{z}_{t-1}+\mathbf{u}_{\mathbf{t}}
$$

where we have stacked the two endogenous variables into the vector

$$
\mathbf{z}_{t}=\left[\begin{array}{c}
r_{t}-r_{t}^{*} \\
\Delta q_{t}
\end{array}\right]
$$

\footnotetext{
${ }^{2}$ We now drop the index for the maturity horizon and use the shorthand notation $r_{t}-r_{t}^{*}$ to denote long-term real interest rate differential at horizon $k$. We will henceforth adopt this simplified notation whenever the exact maturity horizon does not matter in our derivations.
} 
and where $\boldsymbol{\Gamma}$ is a $2 \times 2$ matrix and $\mathbf{u}_{\mathbf{t}}$ an i.i.d. error vector, with covariance matrix $\boldsymbol{\Omega}$. ${ }^{3}$ Now we can use the VAR to back out $\mathbf{E}_{\mathbf{t}} \Delta q_{t+k}$ as

$$
\mathbf{E}\left(\Delta q_{t+k}\right)=\mathbf{e}_{2}^{\prime} \boldsymbol{\Gamma}^{k} \mathbf{z}_{t}
$$

where $\mathbf{e}_{2}^{\prime}=\left[\begin{array}{ll}0 & 1\end{array}\right]$ is the second unit vector.

The strict version of the RERI now imposes a particular set of crossequation restrictions. To see this note that we can write (4) as

$$
\mathbf{E}_{t}\left(q_{t+k}-q_{t}\right)=\mathbf{e}_{2}^{\prime} \sum_{l=1}^{k} \boldsymbol{\Gamma}^{l} \mathbf{z}_{t}=r_{t}-r_{t}^{*}
$$

Since this equation must hold for all possible realizations of $\mathbf{E}_{t}\left(q_{t+k}-q_{t}\right)$ and $r_{t}-r_{t}^{*}$, we obtain the cross-equation restrictions

$$
\mathbf{e}_{2}^{\prime} \sum_{l=1}^{k} \boldsymbol{\Gamma}^{l}=\mathbf{e}_{2}^{\prime} \boldsymbol{\Gamma}\left[\mathbf{I}-\boldsymbol{\Gamma}^{k}\right][\mathbf{I}-\boldsymbol{\Gamma}]^{-1}=\mathbf{e}_{1}^{\prime}
$$

Here, in addition, we have used the formula for the $k$-th partial sum of the geometric series and the fact that $r_{t}-r_{t}^{*}=\mathbf{e}_{1}^{\prime} \mathbf{z}_{t}$.

As we will show, this particular set of restrictions is rejected outright by the data. Nonetheless, we argue that the RERI is a useful starting point for exchange rate modeling if we allow the relationship to be interpreted

\footnotetext{
${ }^{3}$ It is straightforward to generalize the setup to higher order VARs. The model we estimate will generally be of the form $\mathbf{A}(\mathbf{L}) \mathbf{x}_{\mathbf{t}}=\mathbf{x}_{t}-\sum_{l=1}^{p} \mathbf{A}^{l} \mathbf{x}_{t-l}=\mathbf{u}_{t}$ where $\mathbf{A}(\mathbf{L})$ is a matrix polynomial of order $p$ and $\mathbf{x}_{\mathbf{t}}=\left[\begin{array}{cc}r_{t}-r_{t}^{*}, & \Delta q_{t}\end{array}\right]^{\prime}$. In this case,

$$
\boldsymbol{\Gamma}=\left[\begin{array}{cccc}
\mathbf{A}_{\mathbf{1}} & \mathbf{A}_{2} & \ldots & \mathbf{A}_{p} \\
\mathbf{I} & \mathbf{0} & \mathbf{0} & \mathbf{0} \\
: & \mathbf{I} & : & : \\
\mathbf{0} & \ldots & \mathbf{I} & \mathbf{0}
\end{array}\right]
$$

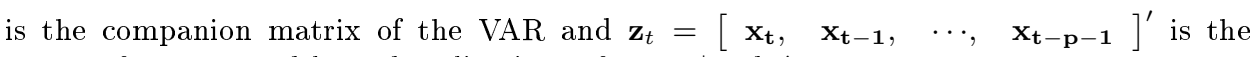
vector of current and lagged realizations of $r_{t}-r_{t}^{*}$ and $\Delta q_{t}$.
} 
more broadly as containing a highly significant and consistently positive link between real interest rate differentials and the expected long-term rate of depreciation of the real exchange rate. At a methodical level, our broader interpretation of the RERI can be thought of as a formalization of the approach advocated by Campbell and Shiller (1987) who have argued that a present value model may well be economically significant, even though its particular cross-equation restrictions may be rejected by the data. Specifically, instead of testing the strict equality $\mathbf{E}_{t}\left(q_{t+k}-q_{t}\right)=r_{t}-r_{t}^{*}$, the variant of the RERI we propose here is one in which we have

$$
\mathbf{E}_{t}\left(q_{t+k}-q_{t}\right)=\beta_{q}\left(r_{t}-r_{t}^{*}\right)+\xi_{t}
$$

with a highly significant and positive $\beta_{q}$ and where a substantial fraction of the variation in $\mathbf{E}_{t}\left(q_{t+k}-q_{t}\right)$ is captured by movements in the interest rate differential and where $\xi_{t}$ is a stationary process. A key element of our approach is that in investigating this formulation of the RERI, we construct $\mathbf{E}_{t}\left(q_{t+k}-q_{t}\right)$ from the forecasting formula (8), i.e. using past realizations of the real interest rate differential.

This broader formulation of the relationship preserves what we view as the spirit of a large literature on the RERI but, as we discuss in detail below, at the same time it also allows for a plethora of plausible economic mechanisms, such as, for example, time-varying currency risk premiums, that we would expect to lead us to reject the much stricter version that is embodied by the set of cross-equation restrictions (10) above. It is not our aim in this paper to provide a particular theoretical explanation of departures from the strict version of the RERI. Rather, as we show below, our estimates of $\beta_{q}$ are all between zero and unity, which allows us to interpret this coefficient as a 
metric that gauges how tight the relation between real exchange rates and real interest rates is in a particular sample.

Our approach offers interesting perspectives on some central aspects of the earlier literature on the RERI. For example, a number of authors (see, inter alia, Meese and Rogoff (1988) and Edison and Pauls (1993)) have sought to test the RERI by attempting to cointegrate the real exchange rate with the real interest rate. However, our discussion above shows that such tests are at best trivial in the sense that since $q_{t}$ is $I(1)$ the only evidence of cointegration (equals stationarity in this context) must come from the interest differential and this is a point made in a different context by both Baxter (1994) and Edison and Melick (1994). Baxter, for example, was among the first to argue that the real interest rate differential should be a stationary variable and therefore correlating it with a non-stationary variable does not make any sense. She proposed correlating the real interest differential with the transitory, or stationary, component extracted from the real exchange rate using both univariate and multivariate Beveridge-Nelson (1981) decompositions. Although Baxter found little support for the RERI when the univariate decomposition was used, clear evidence in support of the RERI emerged using a multivariate decomposition (in the sense that nearly all of the coefficients on the interest differential were significantly positive). Our approach, whilst in the spirit of Baxter, differs in an important respect since our multivariate decomposition involves the real interest rate differential itself. ${ }^{4}$ As we document, this feature is central in capturing the long-term link between the real exchange rate and real interest rate differentials as a significant and consistently positive relationship.

After a brief description of our data, the next section will present the re-

\footnotetext{
${ }^{4}$ Baxter's multivariate decomposition was derived from a bivariate VAR in monthly changes of the real exchange rate and inflation differential.
} 
sults of our empirical implementation of (11) along with a detailed discussion of these issues.

\section{Re-evaluating the RERI}

\subsection{Data}

Our empirical results are based on quarterly bilateral U.S. real exchange rates and real interest rate differentials vis-à-vis the other G7 countries: Japan, Germany, France, Italy, the United Kingdom and Canada. All data are sourced from the December 2008 issue of the IMF's International Financial Statistics (IFS).

The nominal interest rates are long bond yields (line 61) and the price indices are consumer prices (line 64). We constructed bilateral CPI-based real exchange rates vis-a-vis the United States using average quarterly dollar exchange rates (line 132). We consider two sample periods, both starting in 1978Q1: the first, our full sample, stretches through to 2007Q3. ${ }^{5} 6$ We also report results for a pre-EMU sample period that stops a year before the inception of the Euro, in 1997Q4. EMU clearly constituted a major break not only for the participating economies (in our sample Germany, France and Italy are EMU members) but potentially also for the parities between other currencies. As we will see, none of our main findings is affected by the choice of sample period.

\footnotetext{
${ }^{5}$ For the full sample analysis, we simply convert Deutschmark, Franc and Lira exchange rates into Euro at official conversion rates.

${ }^{6}$ We exclude the immediate aftermath of the demise of Bretton Woods and of the first oil shock. Our construction of real interest rates entails proxying for inflation expectations and the instability of the inflation process and, consequently, of the expectation formation process after 1973 is likely to make our econometric proxies of inflation expectations much less reliable. For a similar reason, we also drop the last year of observations available from our data base even though it stretches till 2008Q3: the most recent inflation and CPI releases tend to be very preliminary and are frequently revised. This equally could distort our estimation of inflation expectations.
} 
In order to obtain long-term real interest rates, we first constructed an estimate of average inflation expectations over the maturity horizon of the underlying government bonds (typically 10 years). This was achieved by running a univariate autoregression of CPI-inflation with 5 lags. ${ }^{7}$ We then generated forecasts of quarterly inflation 40 periods ahead. To generate the average expected annual inflation rate we finally divided the cumulative sum of inflation rates by the bond's maturity horizon.

[Figure 1 about here]

As first noted by Baxter (1994), and as discussed above, the RERI can only make sense as an economic relationship if the real interest rate differential is stationary. In our analysis, we follow this prior, treating $q$ as $I(1)$ and $r-r^{*}$ as $I(0)$. and we specify our VARs as in (7) above, with the real interest rate differential in levels and the real exchange rate in differences. In the appendix, we report on the results from a set of unit-root, stationarity and cointegration tests.

\subsection{Results of Present Value tests}

In Figure 1 the data are plotted and an ocular inspection reveals a clear link between real interest rate differentials and exchange rates. Periods of low interest rate differentials coincide with high levels of $q$, i.e. with periods of very depreciated real exchange rates.

\section{[Figures 2-7 about here ]}

\footnotetext{
${ }^{7}$ To check our results for robustness, we varied the lag length in the construction of expected inflation between 1 and 9 lags. All the results in the paper were found to be robust to this change in the construction of real interest rates.
} 
We specified our VARs with seven lags for most countries, although somewhat shorter lag lengths eventually proved sufficient for Canada (3), France (4) and Italy (3). Again, the appendix reports on details of our lag selection procedure. In keeping with the maturity horizons of the government bonds we consider here, we project the expectations 10 years, or 40 quarters, into the future. In Figures 2-7 the expected annualized real rate of depreciation, generated from the VARs, of the US dollar vis-a-vis the currencies of the other G7 countries are plotted. The results are quite striking and would seem to suggest that there is considerable support for the RERI in the data. For virtually all countries, the predicted rate of depreciation is highly correlated with the real interest rate differential, though the interest rate differential is generally more volatile. We also obtain a measure of the uncertainty surrounding our forecast of exchange rate changes based on 100 bootstrap replications. In figures $2-7$, the dotted lines represent the 90 percent quantile of the small sample distribution of $F C$, our estimate of $\mathbf{E}_{t}\left(q_{t+k}-q_{t}\right) .{ }^{8}$ It is noteworthy that the conditional forecast distribution covers the interest rate differential for most of the sample period or is at least very close to it.

The impression obtained from the graphical analysis is confirmed by our formal tests. The first two columns of Table 1 reports the results of regressions of the two time series on each other: as is apparent, the coefficient, though generally smaller than unity, is significantly positive for all six country pairs. This is true in both the pre-EMU and the long sample. For the pre-EMU sample, the $R^{2}$ ranges from a minimum of 0.24 for Canada to

\footnotetext{
${ }^{8}$ It may not be surprising that this quantile almost always covers zero - exchange rate changes are hard to predict, and particularly so based on a VAR deliberately set up as parsimoniously as ours. Thus, while the hypothesis that $F C=0$ is hard to reject at conventional significance levels, the confidence intervals also suggest that the bulk of the probability mass is actually changing the side of zero quite frequently.
} 
0.92 for Germany, suggesting that a substantial fraction of the variation in expected real exchange rate changes can be explained by the real interest rate differential. Conversely, and as we will discuss in detail below, the regression coefficient $\beta_{q}$ can be interpreted as the fraction of the variability in the real interest rate differential that is explained by variation in expected exchange rate changes. Given this interpretation, our estimates here suggest that between around 20 percent (for Italy) and more than 50 percent (for Germany) of the variation in real interest rates are accounted for by changes in exchange rate expectations.

\section{[Table 1 about here]}

For the long sample, the results are qualitatively the same: here, $\beta_{q}$ ranges from 0.27 (Italy) to 0.46 (France). The coefficient $\beta_{q}$ is statistically significant for all six country pairs and the $R^{2}$ ranges from just above 30 percent (Japan) to more than 70 percent for Italy.

It is instructive to compare the results of our analysis to some of the earlier findings in the literature, notably those reported by Baxter (1994). Baxter constructs Beveridge-Nelson (1981) measures of the transitory component of the real exchange rate, $q_{t}^{T}$, and regresses these onto the real interest rate differential. Evidence of significant and, in general, correctly signed links between real exchange rates and real interest rates are reported.

To relate these findings to our own, we provide the results for alternative decompositions of the real exchange rate into permanent and transitory components, including the ones employed by Baxter herself. Specifically, columns 3 and 4 report regressions of the cyclical component of the real exchange rate 
extracted through a univariate HP filter on the real interest rate differential. Columns 5 and 6 report the results from a multivariate Beveridge-Nelson decomposition of the real exchange rate, based on a bi-variate VAR in which the inflation differential figures instead of the real interest rate differential. This is exactly the setup of the VAR used in Baxter (1994).

The results in Table 1 demonstrate that the univariate decomposition is unable to identify a meaningful link between real exchange rates and the real interest rate differential in any instance: the coefficient is virtually always insignificant and often incorrectly signed. This is true irrespective of the sub-period used and very much in line with Baxter's (1994) results. The most important finding here, however, is that the VAR based on the real interest rate differential identifies the hypothesized RERI-link much more consistently than does the VAR based on inflation differentials. While the Baxter VAR sometimes identifies the predicted link with a correct sign, it does not do so consistently. Most importantly, however, the coefficient is generally insignificant, in contrast to the VAR that includes the real interest rate differential, where we found the link to be always significant.

Note also that for both sub-periods, the fit of the regression is generally much higher when $q^{T}$ is constructed from the VAR including the interest rate differential. Another feature that is noteworthy is that for most countries (with the exception of Germany), the coefficient $\beta_{q}$ from the VAR including $r-r^{*}$ is reasonably stable across samples, in spite of the structural break of EMU. We believe these results strongly illustrate the value of including the real interest rate differential in the construction of a transitory component of real exchange rates. ${ }^{9}$

\footnotetext{
${ }^{9}$ We also performed the comparison of the different decompositions on a shorter period, 1974Q2 to 1992Q2, which is almost congruent with Baxter's original sample. The results are qualitatively similar and are therefore not reported here.
} 
While our regression results in Table 1 suggest a much more significant link between the two variables than many previous studies have been able to establish, $\beta_{q}$ is generally not exactly unity nor is the fit of the regression perfect. While this suggests that the strict version of the RERI does not hold, graphs such as those presented in figures 2-7 have, however, played an important role in convincing macro-economists that simple present value models - be it of the New Keynesian Phillips curve (Sbordone (2002)), the term structure of interest rates (Campbell and Shiller (1987)), or of consumption (Campbell (1987)) - should not be dismissed prematurely, even though the exact cross-equation restrictions imposed by these models have often been statistically rejected. In many of these applications, the statistical rejection can be traced back to the fact that the present value model fails to replicate the exact variability of the forecasting, or 'spread', variable, while the model typically does well in terms of the correlation of the predicted value with the 'spread' variable. As our graphs suggest, and as we illustrate further in Table 2, the RERI is no exception in this regard.

\section{[Table 2 about here]}

The last two columns of table 2 report - again for the pre-EMU period and the full sample - the results of the tests of the exact cross-equation restrictions. Note that this test is just another way of establishing that $\beta_{q}$ and the $R^{2}$ associated with the regression (11) are statistically different from unity. It is therefore not surprising that in both sample periods the crossequation restrictions are rejected outright. The first two columns of Table 2 give an initial pass on the source of this rejection. Here, we decompose $\beta_{q}$ into the product of the correlation and the ratio of the standard deviations 
of $\mathbf{E}_{t}\left(q_{t+k}-q_{t}\right)$ and $r_{t}-r_{t}^{*}$. Again, the formal results clearly confirm the graphical impressions: it is mainly the low relative variance of the expected exchange rate change rather than a low correlation that is responsible for the fact $\beta_{q}$ is not generally unity.

For the pre-EMU period, the correlations range from a minimum of 0.49 for Canada to 0.96 for Germany, the average of the correlation coefficients across countries is 0.71 . For the sample running through to 2007Q3, the correlations range from 0.57 (Japan) to 0.86 (Italy), with an average of 0.73 .

Conversely an examination of the relative standard deviations, reported in the second column, reveals that the predicted exchange rate change is generally just half as volatile as the real interest rate differential. In both sample periods, our approach seems to do much better in terms of the correlation between real exchange rates and real interest rates than in terms of their relative volatility. To assess the robustness of this conclusion, we obtain 100 bootstrap replications of the model and tabulate the probability that the correlation coefficient is bigger than $0,0.5$ and 0.8 respectively. The results are given in rectangular brackets in the first column of table 1 . In both sample periods, the probability mass of the empirical distribution of the correlation coefficients is clearly concentrated in the positive unit interval. In the pre-EMU sample, for four out of the six countries (Canada, France, Germany and Italy) at least 50 percent of the bootstrapped correlation coefficients are bigger than 0.5 and for all of these four countries at least around a third even exceed 0.8, with this percentage reaching up to 46 percent for Italy and even 67 percent for Germany. In the long sample, five out of six countries have more than half of the probability mass to the right of one half (Canada, France, Germany, Italy and the United Kingdom). With the exception of Japan and the UK all of these have correlations higher than 
0.8 for more than a third of all simulation draws and, again, Germany and Italy have the bulk of the probability mass of the correlation coefficient to the right of 0.8 .

Hence, the empirical distributions tabulated here suggest that the correlation coefficients are also statistically close to unity. Conversely, the $90 \%$ confidence intervals of the relative standard deviations of the forecasted exchange rate change and the real interest rate differential - reported in parentheses in the second column - do not cover unity in 5 out of six cases, with Germany being the only exception in both sample periods; if the strict version RERI is statistically rejected, it is mainly because expected real exchange rate changes are much less volatile than real interest rate differentials. $^{10}$

Our graphs 2-7, the results in Table 1 and the correlations in Table 2 clearly suggest that there is an economically significant link between real exchange rates and real interest rates. This raises the question of what interpretation should be placed on the rejection of the exact cross-equation restrictions or, equivalently, on the fact that $\beta_{q}$ is not unity. As we will argue next, this fact simply indicates that there is predictability in the excess returns on holding a currency. Since this predictability is a medium-term phenomenon, however, it does not break the long-term link between real exchange rates and real interest rates and therefore does not empirically invalidate the broader concept of the RERI that we advocate to use in confronting the predicted theoretical relationship with the data.

\footnotetext{
${ }^{10}$ We obtained similar results from a trivariate VAR that also included relative output growth as an additional endogenous variable.
} 


\subsection{Economic Interpretation of the cross equation restric- tions and rejection}

In order to understand the meaning of the statistical rejection reported above, we turn to the economic interpretation of the cross-equation restrictions in (9). To this end, we use the definition of the real excess return on holding a currency over $k$ periods as

$$
\sigma_{t}(k)=q_{t+k}-q_{t}-\left(r_{t}(k)-r_{t}^{*}(k)\right) .
$$

Taking expectations, we see that the cross-equation restrictions imply that $\mathbf{E}_{t}\left(\sigma_{t}(k)\right)=0$ - excess returns should not be predictable. Taking conditional expectations, re-arranging terms and taking variances of both sides, we can decompose the variance of the real interest rate differential as

$$
\frac{\operatorname{cov}\left(\mathbf{E}_{t}\left(q_{t+k}-q_{t}\right), r_{t}(k)-r_{t}^{*}(k)\right)}{\operatorname{var}\left(r_{t}(k)-r_{t}^{*}(k)\right)}-\frac{\operatorname{cov}\left(\mathbf{E}_{t}\left(\sigma_{t}(k)\right), r_{t}(k)-r_{t}^{*}(k)\right)}{\operatorname{var}\left(r_{t}(k)-r_{t}^{*}(k)\right)}=\beta_{q}-\beta_{\sigma}=1 .
$$

This decomposition adapts the 'good beta, bad beta' methodology of Campbell and Voultenaaho (2004) to the RERI: in the language of Campbell and Voultenaaho (2004) and Froot and Ramadorai (2005), $\beta_{q}$ can be thought of as measuring the contribution of cash flow news, whereas $\beta_{\sigma}$ measures the impact of expected variation in the discount factor on the interest rate differential. A strict interpretation of the RERI and the cross-equation restrictions implies that $\left[\begin{array}{ll}\beta_{q} & \beta_{\sigma}\end{array}\right]=\left[\begin{array}{ll}1 & 0\end{array}\right]$. Clearly this assumption could be violated if there is a risk premium on the currency that varies in a predictable way. But if there is such a premium, then, according to (13), the real interest rate differential must be correlated with expected excess returns. Hence, either the RERI holds or excess returns on the currency are predictable. It is 
not logically possible to reject both return predictability and the broad version of the RERI. ${ }^{11}$ The joint hypothesis $\left[\begin{array}{ll}\beta_{q}, & \beta_{\sigma}\end{array}\right]=\left[\begin{array}{ll}1, & 0\end{array}\right]$ may well be rejected in the data, and this (together with rejection of $\xi_{t}=0$ ) is what tests of the cross-equation restrictions do indeed suggest. Nonetheless, there may be an economically important link between the real interest rate differential and expected rates of change of the real exchange rate; even though, as we have seen, $\beta_{q}$ may not be identically one, it is still significantly different from zero and positive in the data and the decomposition here suggests interpreting it as a measure of the fraction of the variance in the real interest rate differential that is explained by time variation in expected exchange rate changes.

Table 3 reports the results of the above decomposition. Clearly, $\beta_{q}$ is exactly the coefficient in our broad version of the RERI in (11) that was already presented in Table 1 above:

$$
\mathbf{E}_{t}\left(q_{t+k}-q_{t}\right)=\beta_{q}\left(r_{t}-r_{t}^{*}\right)+\xi_{t}+\text { const },
$$

whereas $\beta_{\sigma}$ is obtained directly from the regression:

$$
\sigma_{t}(k)=\beta_{\sigma}\left(r_{t}-r_{t}^{*}\right)+\nu_{t}+\text { const } .
$$

In the light of the interpretation we have just given, it now becomes clear that the fact that if we consistently reject $\beta_{q}=0$ at very high levels of significance this must imply that changes in expected exchange rate changes explain a significant portion of the variability in $r-r^{*}$. Conversely, the fact that $\beta_{q}$ is generally also significantly different from unity, implies that

\footnotetext{
${ }^{11}$ This result is analogous to Cochrane's (2001) observation that it is not possible to reject both dividend predictability and the predictability of excess returns in a stock price model.
} 
$\beta_{\sigma}=\beta_{q}-1$ must be negative. These findings provide us with an economic interpretation of the rejection of the exact cross-equation restrictions: the interest rate differential has some predictive power for long-term real excess returns on holding the US dollar - a finding which is consistent with the literature on the predictive properties of the forward foreign exchange premium (see Engel (1995) and MacDonald (2006)). But this effect is not sufficiently strong to overturn the RERI - here understood more broadly as an economically significant relation in the data.

\section{[Table 3 about here]}

In fact, our interpretation of $\beta_{q}$ as a metric of the economic significance of the RERI link can be thought of as a formalization of the approach advocated by Campbell (1986). For example, in the context of a test of the permanent income model, Campbell (1986) writes that 'the permanent income hypothesis is worth taking seriously. [...] More generally, models which are strongly rejected statistically may be good approximations of the behavior of economic variables' (p.29). Campbell and Shiller (1987) reach similarly positive conclusions about the term structure model of interest rates, but are more skeptical about the fixed-discount factor model of stock prices. Indeed subsequent to their work, it has been demonstrated that the present-value model of stock prices fails because the dividend price ratio does not reveal variation in dividends; rather, it uncovers variation in both stock prices and excess returns (see the discussion in Cochrane (1994) and Cochrane (2001)).

As our results here show, the strict version of the RERI is also rejected statistically. This rejection can be traced back to the fact there is some predictability in the real excess returns on holding a currency. But as we 
have also shown, in spite of this, there is still an economically significant link between the expected depreciation and the real interest rate differential: a broader version of the RERI explains a significant fraction of the variation in real interest rates and provides a reasonable first-order approximation of expected exchange rate changes. In this respect, the RERI performs at least as well as the relatively more successful implementations of the present value model in other areas, such as the present-value model of consumption. We illustrate this point further in the next section, where we conduct a systematic examination of how the RERI relationship is affected by various types of structural shocks.

\section{Structural shocks to the RERI relation}

Having established that a more broadly interpreted version of the RERI can be identified in the data, we further explore the nature of the link between the two key variables by examining their response to a wide array of macroeconomic shocks. While doing so sheds further light on the RERI as a conditional relationship, we also view this as a way of collecting a set of stylized facts on the dynamic interaction between real interest rates and real exchange rates that may also be of more general interest.

The RERI predicts that fluctuations in the real interest rate differential should be associated with temporary fluctuations in real exchange rates. More specifically, a widening interest rate differential in favour of the home country should be indicative of a future depreciation of the real exchange rate. Given a fixed long-run value of the exchange rate, this implies that the real exchange rate should appreciate after a shock to the real interest rate differential. In our notation, this implies that $q$ will have to drop when $r-r^{*}$ rises: the impact responses of the two variables after a temporary shock 
should have the opposite sign. In this section, we explore this prediction in a structural VAR framework and examine the robustness of our conclusions with respect to different identifying assumptions.

\subsection{Choleski and Blanchard-Quah identification schemes}

Consider again our baseline VAR-specificaton, discussed in section 2 above,

$$
\mathbf{A}(\mathbf{L}) \mathbf{x}_{t}=\mathbf{u}_{t}
$$

where $\mathbf{x}_{\mathbf{t}}=\left[\begin{array}{rl}r-r^{*}, & \Delta q_{t}\end{array}\right]^{\prime}$ and $\mathbf{A}(\mathbf{L})$ a matrix polynomial in the lag operator. Following the structural VAR literature, we postulate that the reducedform residual, $\mathbf{u}_{t}$, is a linear function of the vector, $\mathbf{v}_{\mathbf{t}}$ of structural shocks, so that $\mathbf{u}_{\mathbf{t}}=\mathbf{S} \mathbf{v}_{t}$, where $\mathbf{S}$ is a non-singular square matrix of dimension 2 . Let $\Omega$ be the variance covariance matrix of $\varepsilon_{t}$. Furthermore, we assume that the structural shocks are mutually uncorrelated, so that $\mathbf{E}\left(\mathbf{v}_{t} \mathbf{v}_{t}^{\prime}\right)=\mathbf{I}$ and:

$$
\Omega=\mathbf{S S}^{\prime}
$$

In our two-dimensional VAR, equation (15) imposes three non-redundant restrictions on $\mathbf{S}$. To just-identify the vector of shocks, $\mathbf{v}_{t}$, and the associated impulse response functions, we therefore need an additional restriction. It is customary, to impose $S_{12}=0$, which amounts to a Choleski-decomposition of $\boldsymbol{\Omega}$. However, there is an entire manifold of possible choices for $\mathbf{S}$. Let $\mathbf{S}_{0}$ and $\mathbf{S}_{1}$ be two such alternative choices. Then

$$
\mathbf{v}_{0 t}=\mathbf{S}_{0}^{-1} \varepsilon_{t}=\mathbf{S}_{0}^{-1} \mathbf{S}_{1} \mathbf{v}_{1 t}=\mathbf{P v}_{2 t}
$$


and since both $\mathbf{v}_{0 t}$ and $\mathbf{v}_{1 t}$ have unit variance

$$
\mathbf{I}=\operatorname{var}\left(\mathbf{v}_{0 t} \mathbf{v}_{0 t}^{\prime}\right)=\mathbf{P} \operatorname{var}\left(\mathbf{v}_{1 t} \mathbf{v}_{1 t}^{\prime}\right) \mathbf{P}^{\prime}=\mathbf{P} \mathbf{P}^{\prime}
$$

Hence, the mapping between two orthogonalized shock vectors $\mathbf{v}_{0 t}$ and $\mathbf{v}_{1 t}$, given by $\mathbf{v}_{0 t}=\mathbf{P v}_{1 t}$, is orthogonal. The set of two-dimensional orthogonal matrices can be parametrized as

$$
\mathbf{P}=\left[\begin{array}{cc}
\rho & \sqrt{1-\rho^{2}} \\
\sqrt{1-\rho^{2}} & \rho
\end{array}\right]=\left[\begin{array}{cc}
\cos \lambda & -\sin \lambda \\
\sin \lambda & \cos \lambda
\end{array}\right],
$$

where $-1<\rho<1$ and $0<\lambda<2 \pi$ and therefore we can write $\mathbf{P}$ as a function of $\lambda$, so that $\mathbf{P}(\lambda)$ defines a rotation. Two possible time series of orthogonal shocks $-\mathbf{v}_{0 t}$ and $\mathbf{v}_{1 t}-$ can then simply be rotated onto each other by an appropriate choice of $\lambda$. For an initial choice of $\mathbf{S}_{0}$ with $\mathbf{u}_{t}=$ $\mathbf{S}_{0} \mathbf{v}_{0 t}$, we therefore consider the space of alternative rotations $\mathbf{S}_{\lambda}=\mathbf{P}(\lambda)^{\prime} \mathbf{S}_{0}$, where we let $\lambda$ vary between 0 and $2 \pi$. Each choice of $\lambda$ identifies a vector of mutually orthogonal shocks, $\mathbf{v}_{t}(\lambda)=\mathbf{S}_{\lambda}^{-1} \mathbf{u}_{t}$, to which we can obtain the impulse responses. In this way, we can determine the robustness of our conclusions with respect to the key question addressed here: are shocks to the real interest rate differential associated with temporary fluctuations in the real exchange rate?

Our approach is similar in spirit to that used in King and Watson (1997), who examine the robustness of long-run monetary neutrality under different identification schemes in a bivariate VAR setting. The main difference between our approach and theirs is that King and Watson estimate the contemporaneous interaction between the variables using simultaneous equation methods, whereas in our setting the contemporaneous interaction is given by 
$\mathbf{S}$ which is just identified from the set of orthogonality restrictions (15) and the additional identifying restriction as defined by $\mathbf{P}(\lambda)$.

Clearly, not all choices for $\mathbf{S}_{0}$ and $\mathbf{P}(\lambda)$ are equally plausible. We therefore start by considering two particularly important, and possibly plausible, identifying restrictions on $\mathbf{S}$. The first is the Choleski identification, in which we choose $S_{12}=0$. We will argue that this identification can yield important insights into the economic relevance of the RERI relation. To make this point, we write $\mathbf{x}_{t}$ in moving average form as:

$$
\mathbf{x}_{t}=\mathbf{A}^{-1}(\mathbf{L}) \mathbf{u}_{t}=\mathbf{C}(\mathbf{L}) \varepsilon_{t}=\mathbf{C}(\mathbf{L}) \mathbf{S} \mathbf{v}_{0 t}
$$

where

$$
\mathbf{C}(\mathbf{L})=\mathbf{I}+\sum_{k=1}^{\infty} \mathbf{C}_{k} \mathbf{L}^{k} .
$$

Recall that we defined $\mathbf{x}_{t}=\left[\begin{array}{cc}r_{t}-r_{t}^{*} & \Delta q_{t}\end{array}\right]^{\prime}$, so that the real interest rate differential is ordered first. Hence, with $S_{12}=0$, we identify one shock that affects both the real interest rate differential and the real exchange rate and one shock that only affects the real exchange rate. According to the RERI, the former should: a) have only a transitory effect on the real exchange rate; and b) trigger an impact response of the real exchange rate that has the opposite sign of the response in the real interest rate differential, i.e. $S_{21} / S_{11}<0$. Conversely, permanent variations in the real exchange rate should mainly be driven by those shocks that leave the real interest rate differential unaffected. Therefore, one test of the economic relevance of the RERI is to impose a Choleski identification and to test whether the impulse responses comply with the over-identifying restrictions just discussed.

An alternative test is to use a long-run identification in the spirit of 
Blanchard and Quah (1989). Such a restriction can be applied to the RERI by requiring that shocks to the interest rate differential should not have a long-run impact on the real exchange rate. We obtain this restriction by acknowledging that the long-run response of $\mathbf{x}_{t}$ is given by $\mathbf{D}(\mathbf{1})=\mathbf{C}(\mathbf{1}) \mathbf{S}$. Given the ordering of our variables, requiring that the shock to the interest rate differential does not have an impact on the long-run level of the exchange rate, this amounts to $D_{21}=0 .{ }^{12}$ Here, the set of over-identifying restrictions implied by the RERI would be that the transitory shock should account for the bulk of the dynamics in the real interest rate differential and that the response of the interest rate differential to such a shock should have the opposite sign of the real exchange rate response.

\subsubsection{Impulse response results}

From our discussion, it is apparent that the RERI actually implies that both the Choleski and the Blanchard-Quah decompositions should give us the same pattern of responses: the response to the transitory shock in the Blanchard-Quah decomposition should just correspond to the response to an interest rate shock in the Choleski-decomposition.

[Figure 8 about here ]

For all six country pairs, Figure 8 presents the impulse responses of the VAR in (14) obtained under the Choleski and the Blanchard decompositions, respectively. ${ }^{13}$ The first key point to note from these graphs is that

\footnotetext{
${ }^{12}$ Under the Blanchard-Quah scheme it is generally the upper right entry in $\mathbf{D}(\mathbf{1})$ that is restricted to zero. In our setup here, the non-statioanry variable, $q_{t}$ is ordered second, however, so that the Blanchard-Quah restriction amounts to setting the lower right entry of $\mathbf{D}(\mathbf{1})$ to zero.

${ }^{13}$ In this and the following subsection, we present impulse responses for the full sample period, 1978Q1-2007Q3. Results for the pre-EMU sample are very similar.
} 
the choice between the two identification schemes does not strongly affect the results: the responses obtained under the Choleski and the BlanchardQuah schemes move very closely together in all six countries. In many cases, the Blanchard-Quah response even falls into the 90 percent bootstrapped confidence interval of the Choleski decomposition, so that - at least in a macroeconomic sample of the size we have here - it is statistically impossible to tell the two identification schemes apart. Even more encouragingly, the relative sign of the responses matches the predictions of the RERI - a transitory appreciation of the real exchange rate is typically associated with an increase in the real interest rate differential.

Again, we conclude from these findings that predictable variation in the discount factor may lead to a statistical rejection of the strict form of RERI, but that this does not invalidate a broader concept of the RERI as an economically significant relationship. Our response analysis suggest that the dynamic implications predicted by the theory are - at least qualitatively very much supported by the data.

\subsection{Robustness to alternative identification schemes}

Theoretical considerations suggest that the Blanchard-Quah and Choleski decompositions deserve special consideration in the context of the RERI. As we discussed initially, there is an infinity of potential identification schemes, and, clearly, not all of these schemes are equally plausible on economic grounds. But it is nonetheless informative to examine the robustness of our conclusions with respect to different identification schemes for the structural shocks.

According to equations (16) and (17), any possible identification of structural shocks to the RERI can be recovered through an appropriate rotation of 
the shocks recovered from the Choleski-identification. Let $\mathbf{S}_{\lambda}$ be any matrix fulfilling the orthogonality restrictions (15), then

$$
\mathbf{S}_{\lambda}=\mathbf{P}(\lambda)^{\prime} \mathbf{S}_{C h o l}
$$

for some rotation matrix $\mathbf{P}(\lambda)$. Hence, in order to explore how the RERI relationship is affected by different identifying assumptions, we simply have

to vary $\lambda$. Specifically, we choose values of $\lambda$ in the interval $[0,2 \pi]$ with a step width of one degree, i.e. $2 \pi / 360$. For each $\mathbf{S}_{\lambda}$ thus obtained, we obtain the impulse responses to the two structural shocks. We normalize the interest rate response to the first shock and the exchange rate response to the second shock to be positive. For convenience we therefore continue to call the first shock the interest rate shock and the second the exchange rate, or excess-return, shock. We then average the impulse response functions over the 360 different realizations and we also calculate the median response in order to obtain an impression of the distribution of the underlying responses. The results of this exercise are plotted in Figure 9, panels a-f.

\section{[Figure 9 about here]}

The characteristic pattern of the response to an interest rate shock that we established from the Choleski- and Blanchard-Quah decompositions, turns out to be very robust to changes in the identifying assumptions: for most countries, the first shock leads to a fall - an appreciation - in the real exchange rate upon impact. This appreciation is then generally offset as the interest rate differential starts to narrow. In the long-run, this shock does generally not have a pronounced (and significant) impact on the real exchange rate. The second (excess return) shock generally has a permanent 
effect on the exchange rate and it is also generally associated with temporary fluctuations in the real interest rate differential, but only to the extent that the real exchange rate initially under-adjusts to the permanent shock. The message from the various panels in Figure 9 is the same, irrespective of whether we consider the median or the average response. We note, however, that the stylized pattern is generally even more pronounced once we consider the median response, and particularly for the real exchange rate. This suggests that for the majority of all possible identification restrictions, the response of the two variables to structural shocks complies qualitatively very well with the predictions of the RERI.

\section{Conclusion}

In this paper we have re-examined the real exchange rate - real interest rate (RERI) relationship using data for six US dollar bilateral exchange rates, over the period 1978 to 2007. Many previous tests of this relationship have involved attempting to cointegrate measures of a real exchange rate with a measure of a country's real interest differential. However, following Baxter (1994), the derivation of the RERI relationship suggests that such a method is likely to be flawed since if the real exchange rate is integrated of order one, the real interest differential must be stationary.

Building on this insight, we proposed interpreting the RERI by building on the VAR-based approach for present value models of Campbell and Shiller (1987) . This involves taking the projection of the change in the real exchange rate from a bivariate VAR, consisting of the change in the real exchange rate and the real interest differential, and correlating it with the real interest differential. We argued that this kind of test is much closer in spirit to the RERI relationship than many extant tests, and it produces measures of long- 
run expected changes in the exchange rate which are highly correlated with real interest rate differentials.

While the particular set of cross-equation restrictions that arise from a fixed-discount factor model are statistically rejected, our framework allows us to trace this back to the presence of predictable excess returns. We show that this rejection does not invalidate the RERI link as an economically significant relationship: a significant fraction of the variability in real interest rate differentials is explained by time-variation in expected exchange rate changes and real interest rate differentials are highly correlated with measures of the expected rate of depreciation.

The upshot of our results is that the RERI is no more elusive than other important relationships in macroeconomics and finance that have been tested in a present value context, such as: the stock price / dividend relationship; the consumption - income relationship; the term structure of interest rates and the new Keynesian Phillips-Curve. Such models are often statistically rejected in a present value setting, but the statistical rejection is usually associated with a fixed discount-factor assumption. As argued by Campbell (1986), such rejections per se are not informative with respect to the economic significance of a particular theory. Our approach formalizes this philosophy in the sense that, instead of focusing on the cross-equation restrictions implied by a particular incarnation of the theory, we have proposed a metric of the economic significance of the hypothesized theoretical link. Clearly, this approach can be generalized to other theoretical relationships than the RERI.

We provide further evidence in support of the RERI by identifying structural shocks to the RERI relationship. We find that shocks to the real interest rate differential, in general, only produce temporary responses in the real ex- 
change rate and these responses have the right sign: on impact, a widening interest rate differential leads to a temporary appreciation that is then offset through a subsequent depreciation as relative price levels start to converge and as the interest rate differential starts to narrow again. This result turns out to be independent of the particular identification scheme imposed on our VAR model. The evidence we have reported in this paper therefore strongly supports the conclusion that the RERI as an economic relationship should be taken seriously: real interest rate differentials constitute a good proxy for the temporary component in real exchange rates!

\section{References}

[1] Baxter, M. (1994), 'Real Exchange Rates and Real Interest Rate Differentials: Have we Missed the Business Cycle Relationship?' Journal of Monetary Economics.(33) 1 pp. 5-37.

[2] Beveridge, S. and C.R. Nelson (1981), 'A New Approach to the Decomposition of Economic Time Series into Permanent and Transitory Components, with Particular Attention to the Measurement of Business Cycles', Journal of Monetary Economics, 7, 151-74.

[3] Blanchard, Olivier J. and Danny Quah (1989). 'The Dynamic Effects of Aggregate Demand and Supply Disturbances.' American Economic Review 79, 655-673.

[4] Campbell, John Y. (1986). 'Does Saving Anticipate Declining Labor Income? An Alternative Test of the Permanent Income Hypothesis', NBER working paper 1805. (Revised version published in Econometrica $55(6), 1249-1273$.

[5] Campbell, J. and Pierre Perron (1991). "Pitfalls and Opportunities: What Macroeconomists Should Know about Unit Roots", NBER Macroeconomics Annual, vol. 6, 141-201. 
[6] Campbell, J and R. Shiller (1987), 'Cointegration Tests of Present Value Models', Journal of Political Economy, Vol 95, 1062-88

[7] Campbell, J. and Shiller, R. (1988). 'The Dividend-Price Ratio and Expectations of Future Dividends and Discount Factors', Review of Financial Studies, 1, 195-227.

[8] Campbell, John Y. and Tuomo Vuolteenaho (2004). 'Good beta, bad beta', American Economic Review, vol. 94(5).

[9] Cochrane, John H. (1994). 'Permanent and Transitory Components of GDP and Stock Prices.' Quarterly Journal of Economics 109, 241-265.

[10] Cochrane, John H. (2001). Asset Pricing, Princeton NJ: Princeton University Press.

[11] Dornbusch, R. (1976), 'Expectations and Exchange Rate Dynamics', Journal of Political Economy, 84, 1161-76.

[12] Edison, H. J., and D. Pauls (1993) "A Re-Assessment of the Relationship Between Real Exchange Rates and Real Interest Rates: 1974-90"' Journal of Monetary Economics, Vol. 31, pp. 165-87.

[13] Edison, H. and W.R. Mellick (1994) 'Alternative Approaches to Real Exchange Rates and Real Interest Rates: Three Up and Three Down' Board of Governors of the Federal Reserve System, International Finance Discussion Papers No 518

[14] Engel, C. (1995), "The Forward Discount Anomaly and the Risk Premium: A Survey of Recent Evidence", Journal of Empirical Finance, 3, 123-192.

[15] Engel, Charles and Kenneth D.West (2004) 'Accounting for Exchange Rate Variability in Present Value Models when the Discount Factor is Near One', American Economic Review, Papers and Proceedings 94, May 2004, 119-125.

[16] Froot, K. A., and T. Ramadorai (2005). "Currency Returns, Intrinsic Value, and Institutional Investor Flows." Journal of Finance 60, no. 3 (June): 1535-1566. 
[17] Grilli, V. and N. Roubini (1992), "Liquidity and Exchange Rates", Journal of International Economics, 32, 339-352.

[18] Hoffmann, Mathias (2003). "International Macroeconomic Fluctuations and the Current Account.", Canadian Journal of Economics, vol. 36 no. 2 (May), pp. 401-420.

[19] King, Robert G. and Mark W. Watson (1997). 'Testing Long-Run Neutrality' Federal Reserve Bank of Richmond Economic Quarterly Volume 83/3 (Summer 1997).

[20] Kwiatowski, Denis, Phillips, P.C.B., Schmidt, Peter and Yoncheol Shin (1992)."Testing the null hypothesis of stationarity against the alternative of a unit root", Journal of Econometrics (54), 159-178.

[21] Lütkepohl, Helmut (2006) New Introduction to Multiple Time Series Analysis, Berlin: Springer-Verlag.

[22] MacDonald, R. (2006), The Economics of Exchange Rates: Theories and Evidence, Second Edition London: Routledge

[23] Meese, R, and K. Rogoff (1988), "Was it real? The exchange rateinterest differential relation over the modern floating rate period", Journal of Finance, 14, 3-24.

[24] Mussa, M. (1984), 'The Theory of Exchange Rate Determination', in Exchange Rate Theory and Practice, NBER Conference Report (eds) J.F.O. Bilson and R.C. Marston, Chicago: Chicago University Press.

[25] Mussa, M. (1986), 'Nominal Exchange Rates and the Behaviour of Real Exchange Rates: Evidence and Implications', Carnegie Rochester Series on Public Policy, 26.

[26] Newey, W. and K. D. West (1987). "A simple, positive definite, heteroskedasticity and autocorrelation consistent covariance matrix." Econometrica 55:3;703-708.

[27] Obstfeld, M. and K. Rogoff (1996), Foundations of International Macroeconomics, MIT Press.

[28] Sbordone, Argia (2002). 'Prices and Unit Labor Costs: A New Test of Price Stickiness. ' Journal of Monetary Economics vol. 49 (2), 265-292. 
Appendix: Unit root, stationarity and cointegration tests; VAR specification For both the real exchange rate and the real interest rate differential, Table A1 reports the results from augmented Dickey-Fuller tests of the null of a unit root. Since our maintained hypothesis for the real interest rate differential is that of stationarity, we also report tests of the null of stationarity based on Kwiatowski et al. (1992), the so-called KPSS test.

As is apparent, unit root tests never reject the unit root in real exchange rates. Though the same is true for the real interest rate in most cases, we can equally often not reject the null when, instead of tests of the null of non-stationarity, we test the null of stationarity (KPSS). In fact, only for Germany and Italy both types of test would suggest that real interest rates are non-stationary whereas for France and Japan, they would unequivocally suggest that they are stationary. For Canada and the UK we obtain contradictory results. Hence, these tests offer little guidance in specifying the model. The evidence is somewhat more conclusive - and points in the direction of our prior - when we treat both real interest rates and real exchange rates as a potentially cointegrated system. Though we find that there is usually no evidence for cointegration when asymptotic critical values are used, it is known that cointegration tests, as in the case of univariate unit root tests, have low power in typical macroeconomic sample sizes. We therefore also estimated the system with one cointegrating restriction imposed. In this case, the implied cointegration vector generally comes close to a unit vector in the sense that the coefficients on $r-r^{*}$ are unity and the one on $q$ zero. In fact, we cannot reject that the cointegrating vector is $\left[\begin{array}{ll}1 & 0\end{array}\right]^{\prime}$ in four out of six cases. We conclude from these results that the real interest rate differential, though clearly very persistent, is a mean reverting process. We then follow Campbell and Shiller (1987) and Campbell and Perron (1991), who have argued that, if there are a priori economic reasons to do so, imposing cointegration restrictions will improve the approximation of the short-term dynamics (and forecasting properties) of the econometric model. Hence, we specifiy the system as one in which the real interest rate differential is stationary and where $q$ is treated as $I(1)$. As Campbell and Shiller (1987) have shown and as is discussed in some detail in Hoffmann (2003), it is valid to represent an $n$-dimensional cointegrated system in the format (7), i.e. with the $h$ stationary relations (here $h=1$, corresponding 
to $r-r^{*}$ itself) in levels and the $n-h$ non-stationary (trend) variables in differences.

In specifying our VAR, we test for the lag order using the method advocated by Campbell and Perron (1991): starting from some $k^{\max }$ and counting $k$ down to 1 , we test if the $k$-th lag is (jointly) significant. The first $k$ smaller or equal than $k^{\max }$ for which this is the case is a consistent estimate of the true lag order. As our starting value we choose $k^{\max }=10$. Since our interest here is in exploring the long-run relation between $r-r^{*}$ and $q$, we augment the lag order relative to the Campbell-Perron $k$, typically by one or two lags. The numbers given in the main text refer to these augmented lag orders. As discussed in Luetkepohl (2006), lag augmentation can considerably improve the finite sample properties of tests on the long-run coefficients of the model (e.g. over-identifying or Granger causality tests as we consider them here) if the regressors are very persistent. To check that our results are not unduly affected by this lag augmentation, we also compared our results to those obtained when the lag orders estimated from the first stage Campbell-Perron procedure were imposed. 


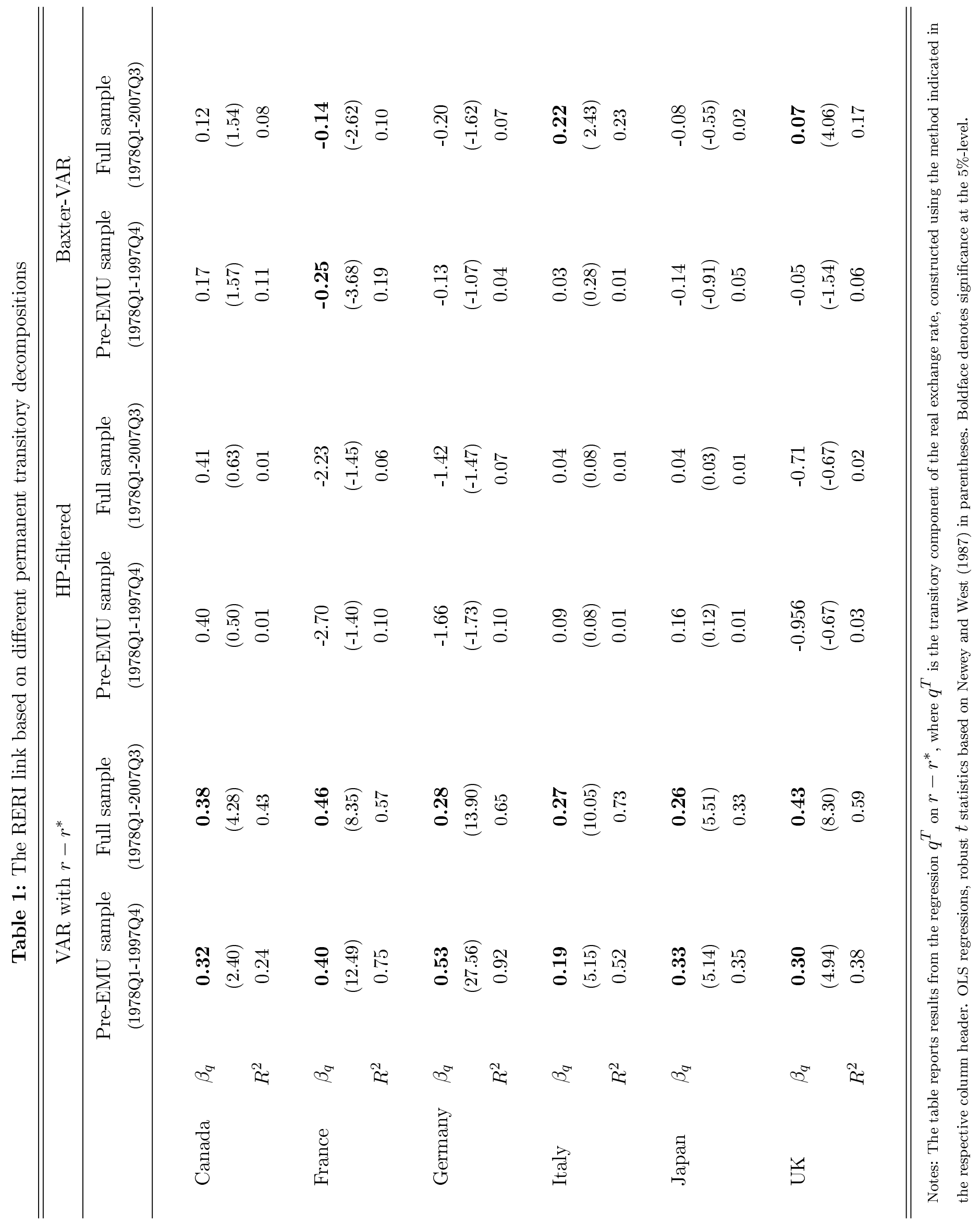




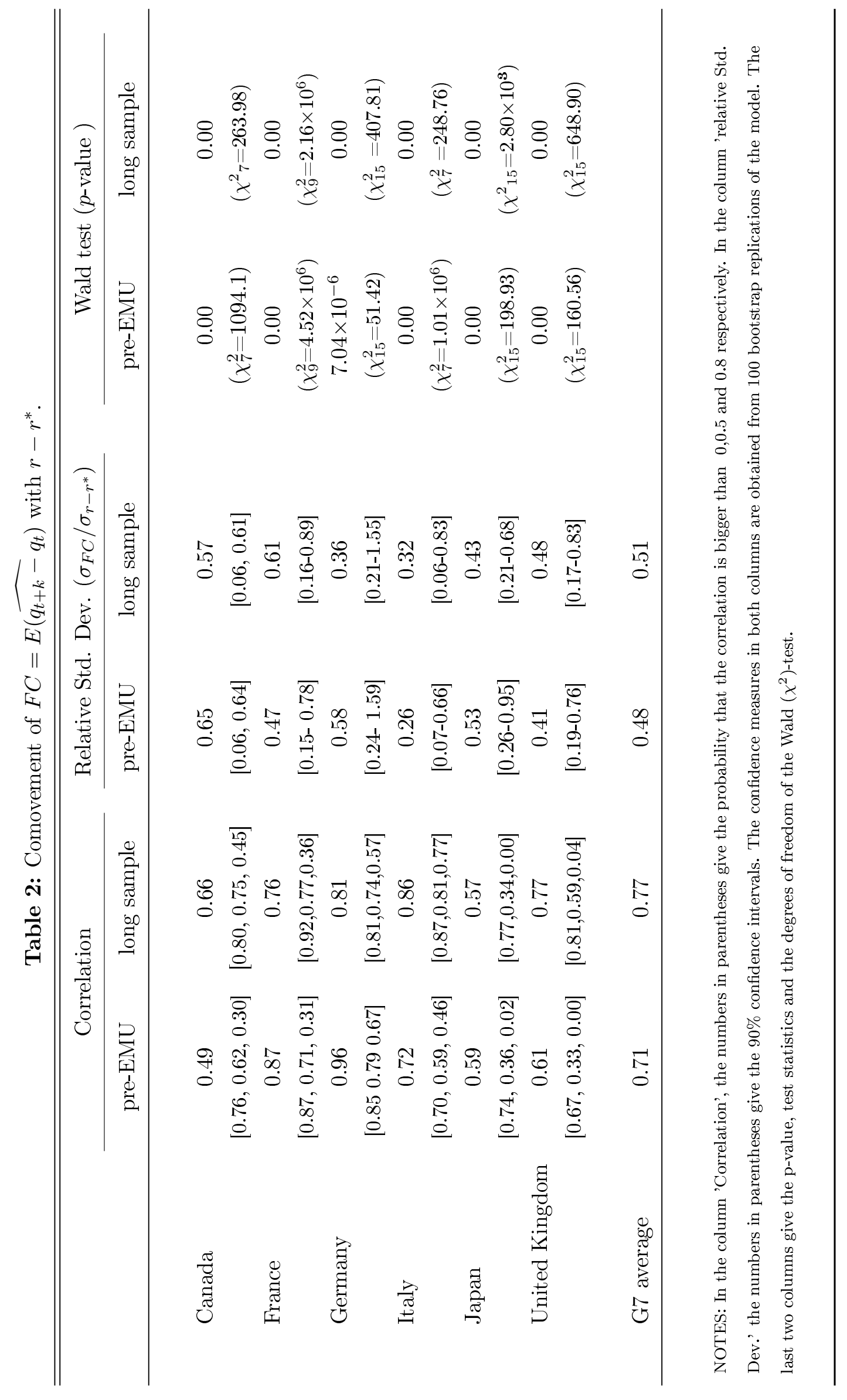


Table 3: Variance decomposition of $r(k)-r^{*}(k)$

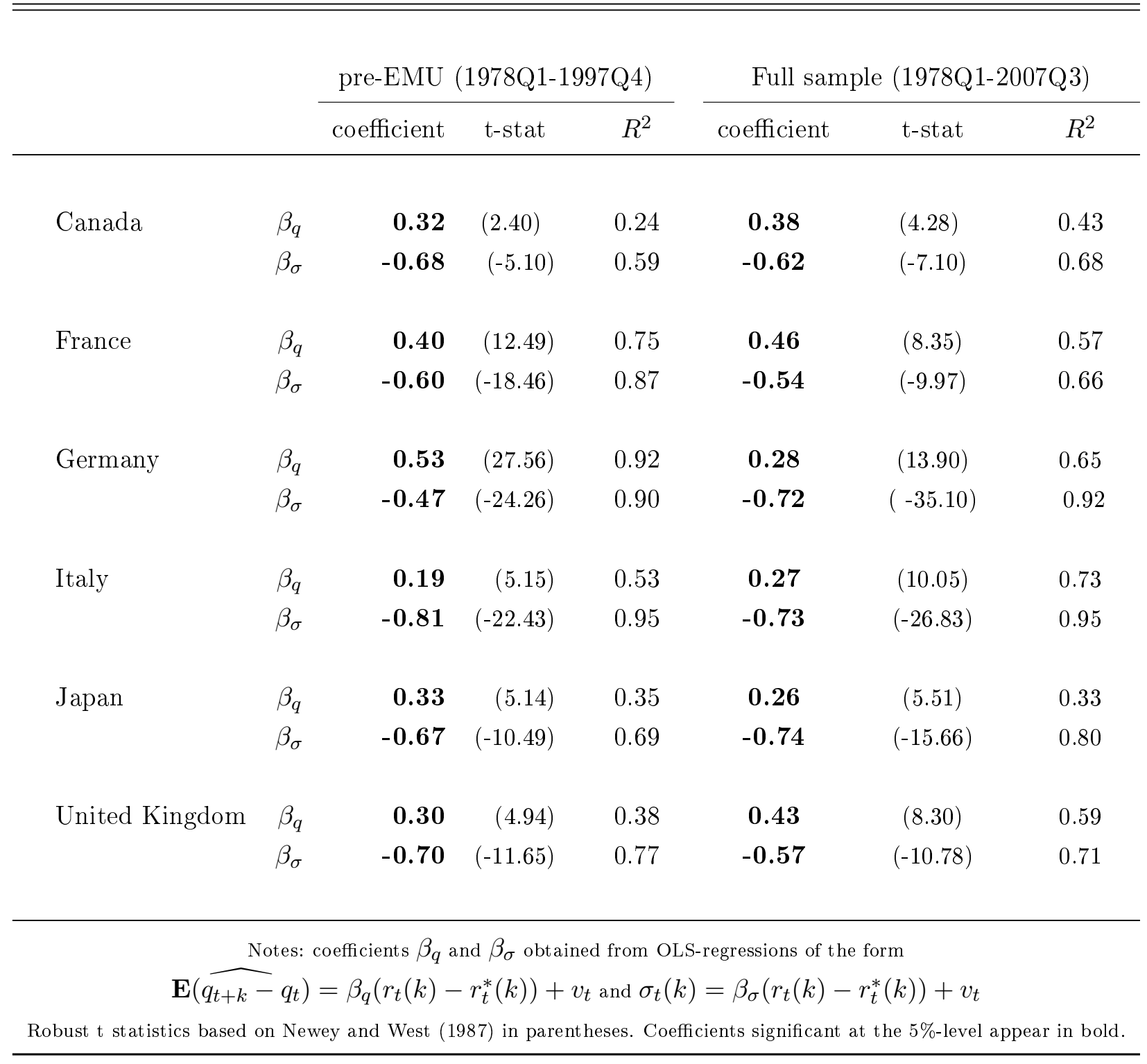


Table A1: Unit root and stationarity tests

\begin{tabular}{|c|c|c|c|c|c|c|c|}
\hline & & & \multicolumn{5}{|c|}{ "lag length } \\
\hline & & & 0 & 1 & 3 & 5 & 7 \\
\hline \multirow[t]{3}{*}{ Canada } & $\mathrm{ADF}$ & $q$ & -0.93 & -1.19 & -1.49 & -1.78 & -1.84 \\
\hline & & $r-r^{*}$ & -2.70 & -2.67 & -1.78 & -1.58 & -1.67 \\
\hline & KPSS & $r-r^{*}$ & 1.49 & 0.80 & 0.44 & 0.32 & 0.25 \\
\hline \multirow[t]{3}{*}{ France } & $\mathrm{ADF}$ & $q$ & -1.64 & -2.35 & -2.73 & -2.94 & -2.91 \\
\hline & & $r-r^{*}$ & -3.98 & -3.97 & -3.53 & -3.30 & -2.28 \\
\hline & KPSS & $r-r^{*}$ & 1.00 & 0.57 & 0.35 & 0.27 & 0.24 \\
\hline \multirow[t]{3}{*}{ Germany } & $\mathrm{ADF}$ & $q$ & -1.76 & -2.31 & -2.94 & -2.92 & -2.76 \\
\hline & & $r-r^{*}$ & -1.83 & -1.78 & -1.93 & -1.75 & -1.55 \\
\hline & KPSS & $r-r^{*}$ & 5.18 & 2.66 & 1.39 & 0.97 & 0.76 \\
\hline \multirow[t]{3}{*}{ Italy } & $\mathrm{ADF}$ & $q$ & -1.51 & -2.13 & -2.46 & -2.43 & -2.33 \\
\hline & & $r-r^{*}$ & -2.07 & -2.22 & -2.08 & -2.12 & -1.30 \\
\hline & KPSS & $r-r^{*}$ & 4.40 & 2.29 & 1.23 & 0.87 & 0.70 \\
\hline \multirow[t]{3}{*}{ Japan } & $\mathrm{ADF}$ & $q$ & 1.40 & -1.88 & -1.97 & -1.81 & -1.73 \\
\hline & & $r-r^{*}$ & -2.64 & -2.84 & -3.46 & -3.93 & -2.34 \\
\hline & KPSS & $r-r^{*}$ & 0.44 & 0.23 & 0.13 & 0.10 & 0.08 \\
\hline \multirow[t]{3}{*}{ UK } & $\mathrm{ADF}$ & $q$ & -1.50 & -2.05 & -2.02 & -1.77 & -2.59 \\
\hline & & $r-r^{*}$ & -3.12 & -3.05 & -3.33 & -2.90 & -2.92 \\
\hline & KPSS & $r-r^{*}$ & 2.73 & 1.43 & 0.77 & 0.56 & 0.46 \\
\hline
\end{tabular}

NOTES: The table reports the augmented Dickey Fuller (ADF) and Kwiatowski et al. (KPSS) test statistics. Column headings indicate the lag order used for the approximation of the unconditional variance of the residual process. The ADF tests the null of a unit root against a stationary alternative, the KPSS-test has stationarity as the null. The $5 \%$ critical value for the ADF test is -2.91 , for the KPSS-test it is 0.436 ( 0.347 at the $10 \%$ level). Significant rejections of the null are highlighted in bold. Sample period is 1978Q1 to 2007Q3. 

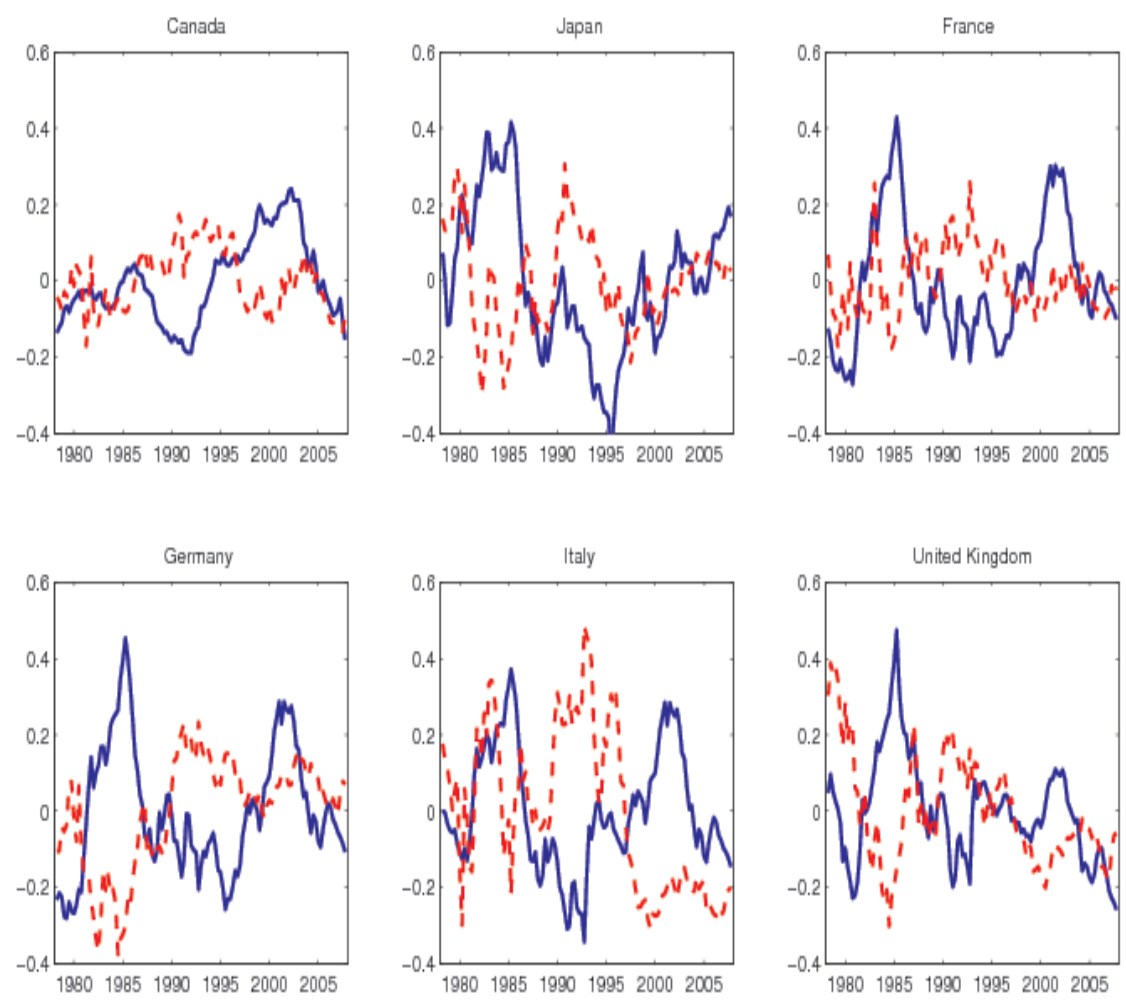

Figure 1: U.S. bilateral CPI real exchange rates (solid line) and real interest differential (in $\% * 10^{-1}$ ) 


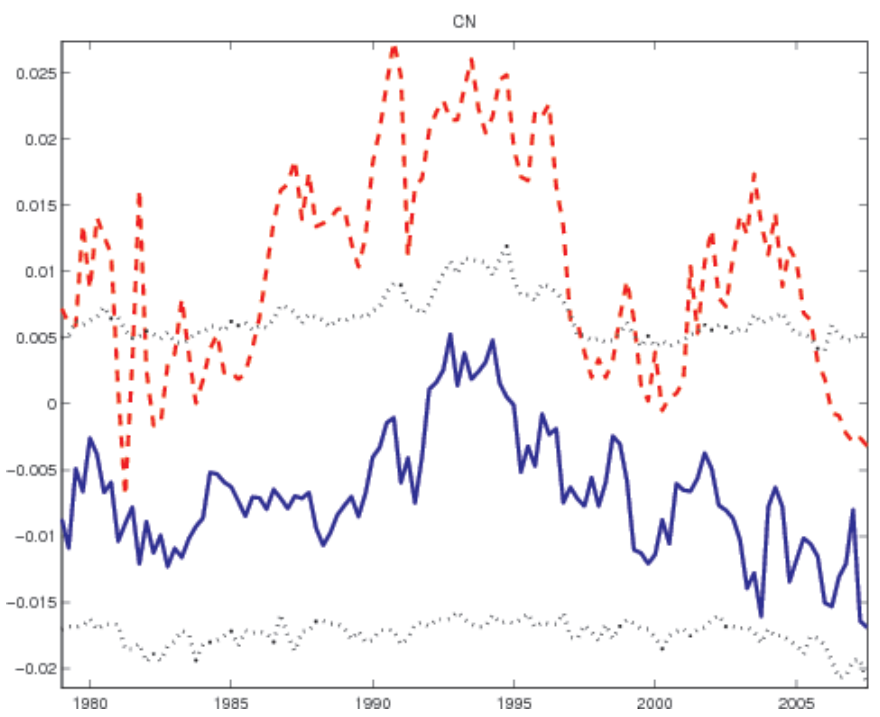

Figure 2: Canada - Expected Rate of Depreciation, $F C=\mathbf{E}_{t}\left(\widehat{q_{t+k}}-q_{t}\right)$, (solid/blue) and real interest rate differential (dashed/red). Dotted/black line gives $90 \%$ confidence intervals of $F C$.

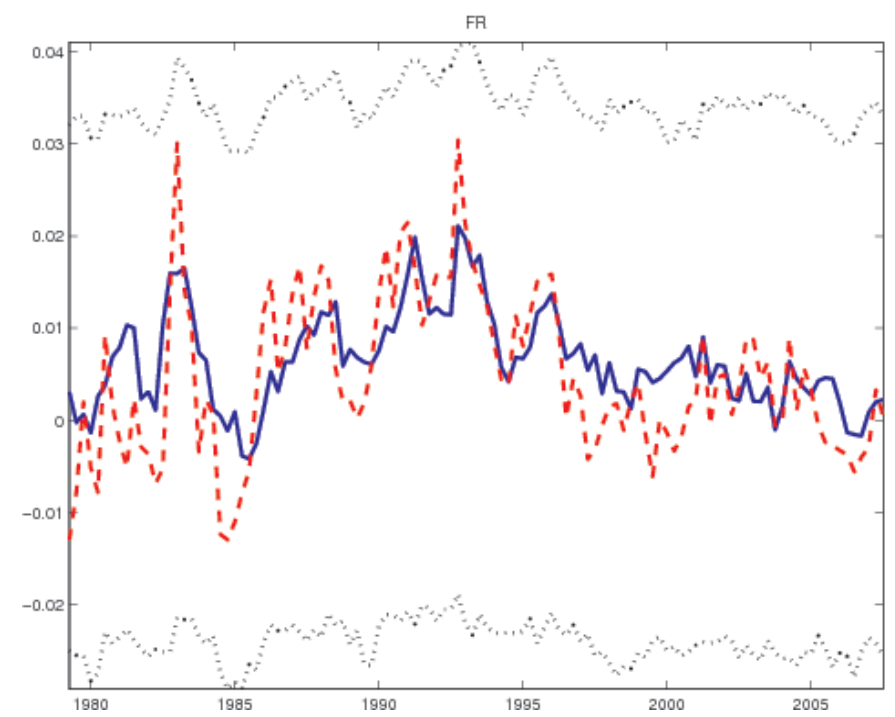

Figure 3: France - for notes see figure 2. 


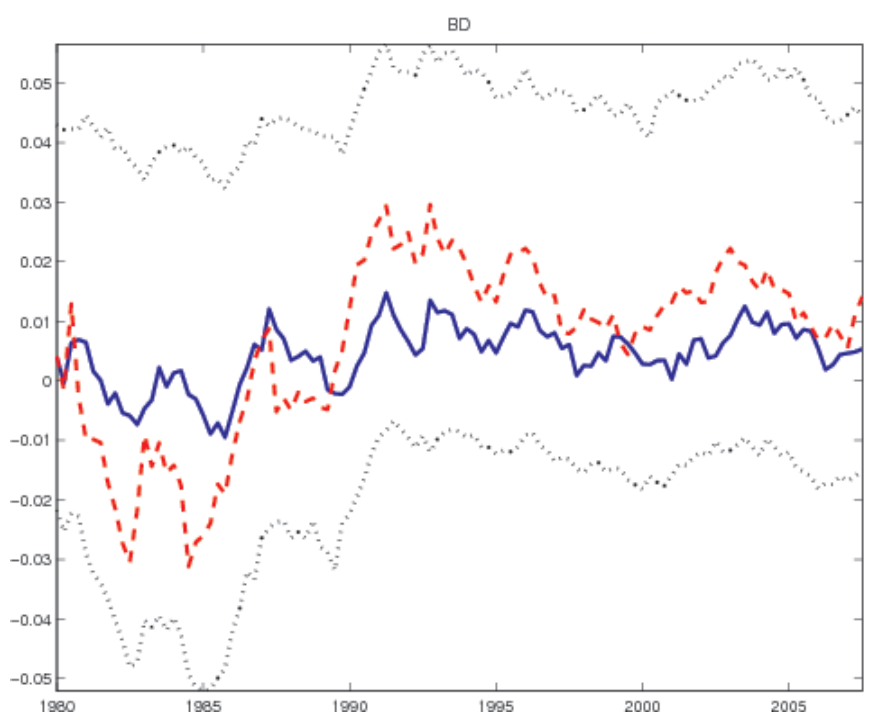

Figure 4: Germany - for notes see figure 2

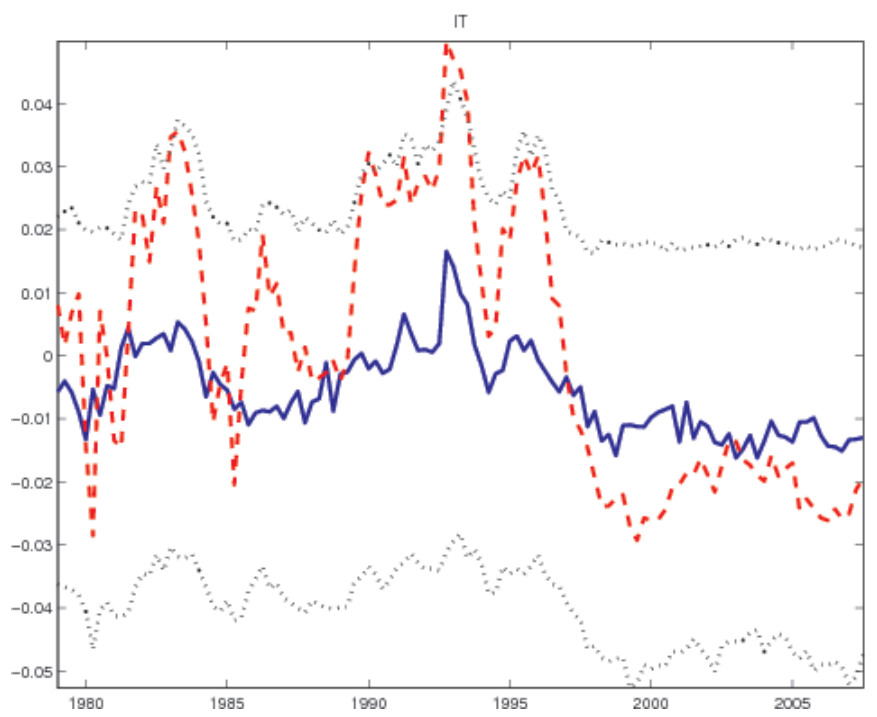

Figure 5: Italy - for notes see figure 2 


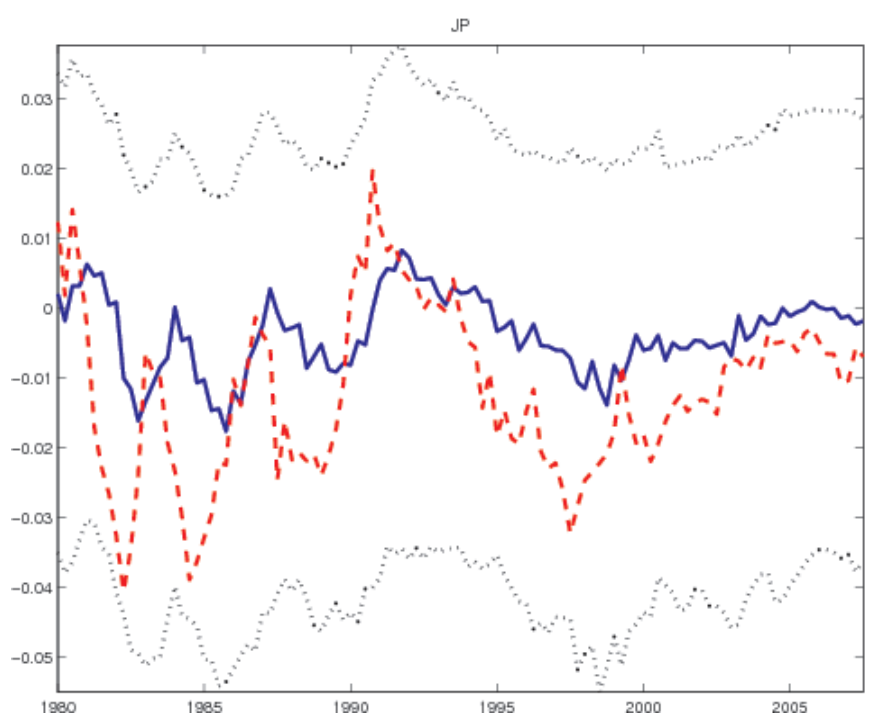

Figure 6: Japan - for notes see figure 2

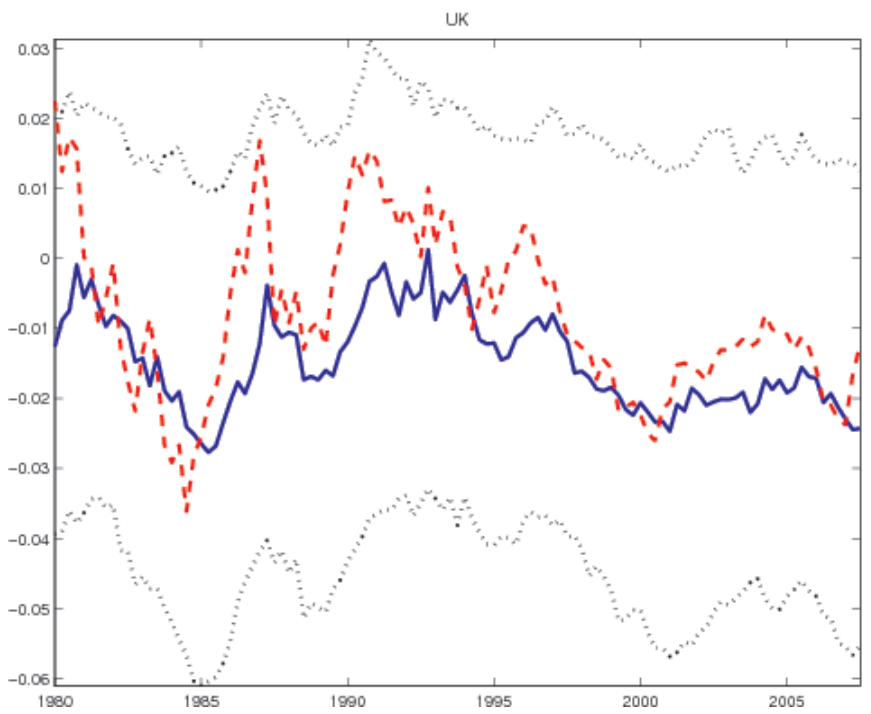

Figure 7: United Kingdom - for notes see figure 2 
Figure 8: Impulse responses obtained from Choleski and BQ-decompositions

a) Canada
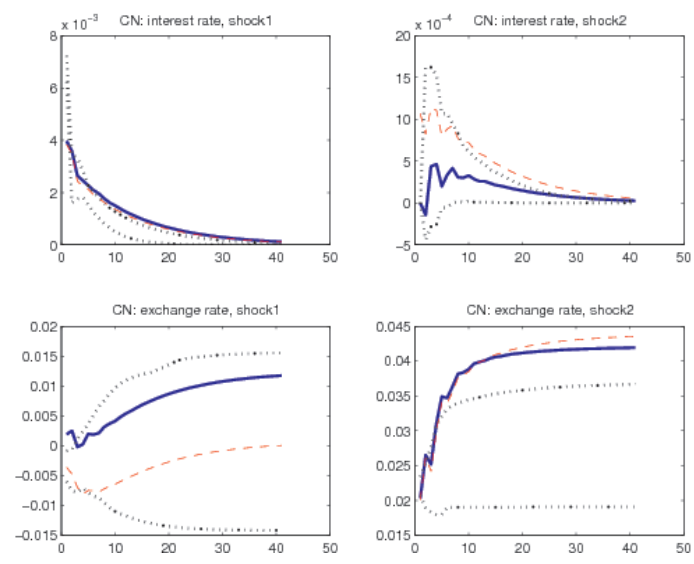

c) Germany
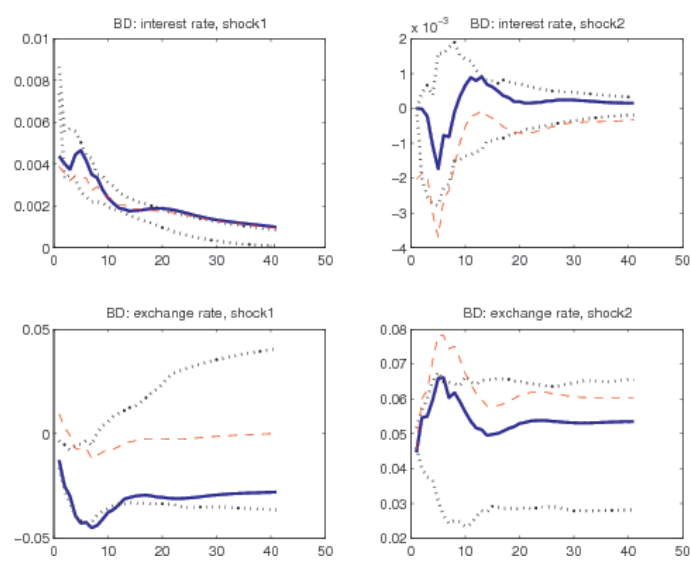

e) Japan
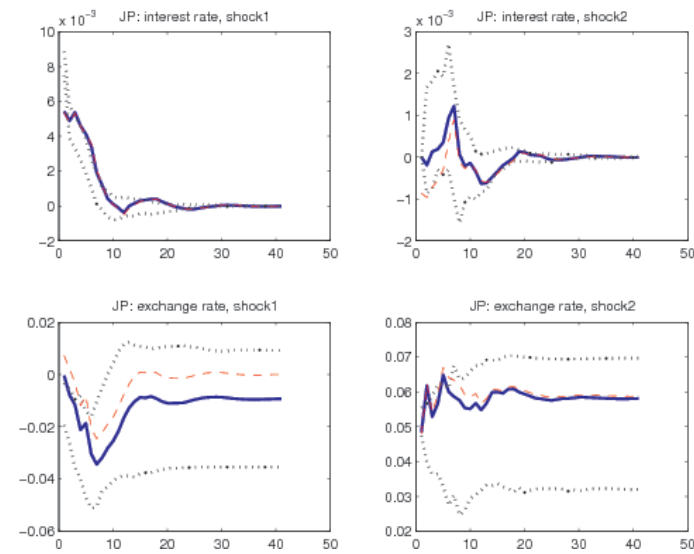

b) France
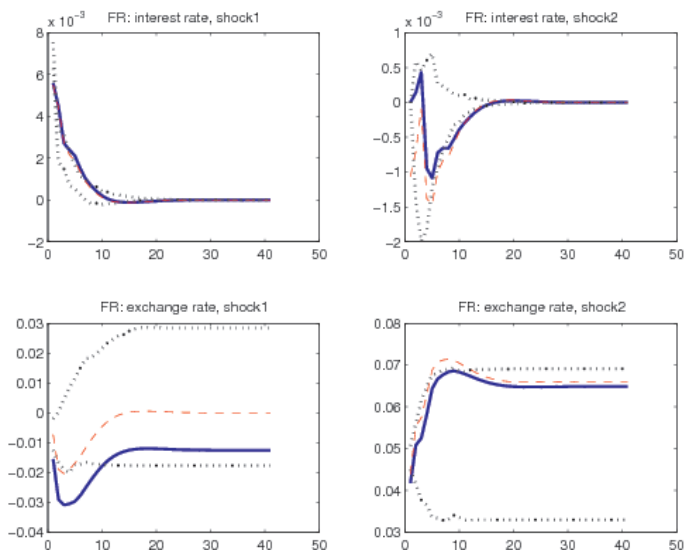

d) Italy
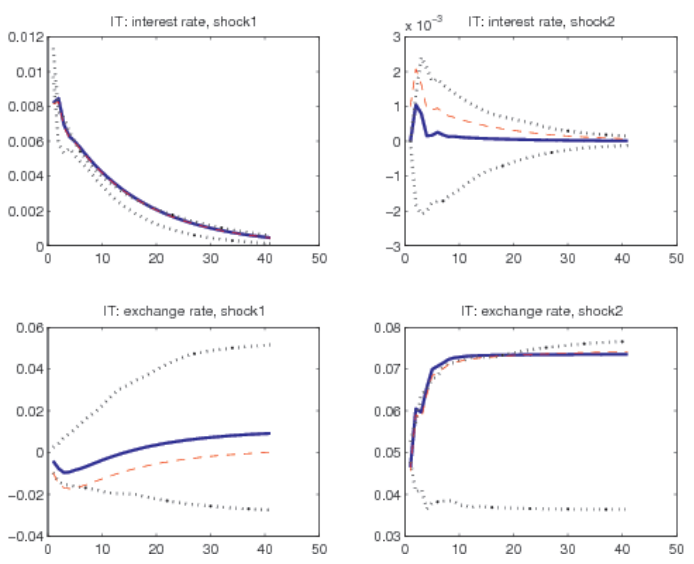

f) United Kingdom
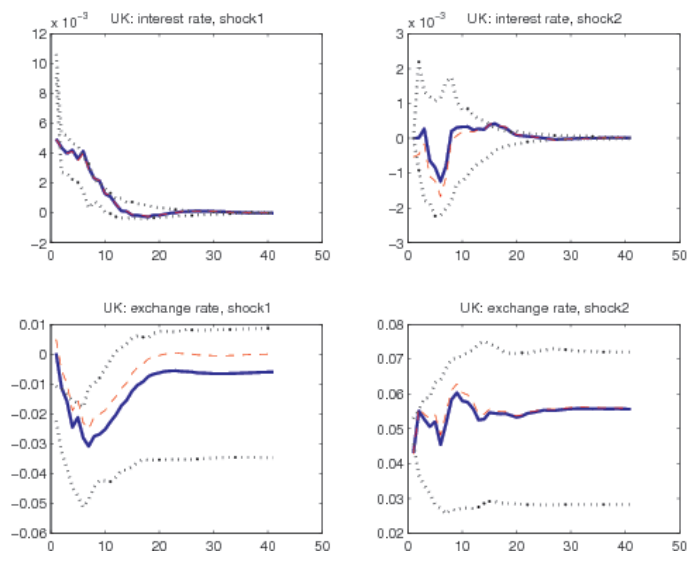

NOTES: Impulse responses based on Choleski (blue, solid) and Blanchard-Quah (red, dashed) identification schemes. Black, dotted lines are $10 \%$ confidence intervals of the Choleski-based response obtained by 100 bootstrap replications. Sample period is 1978 Q2 to $2007 \mathrm{Q} 3$ 
Figure 9: Average and median Impulse responses obtained through rotation

a) Canada
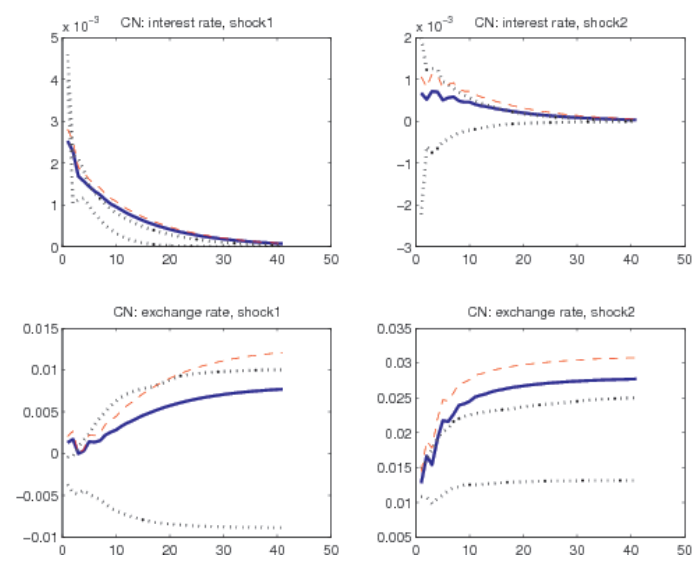

c) Germany
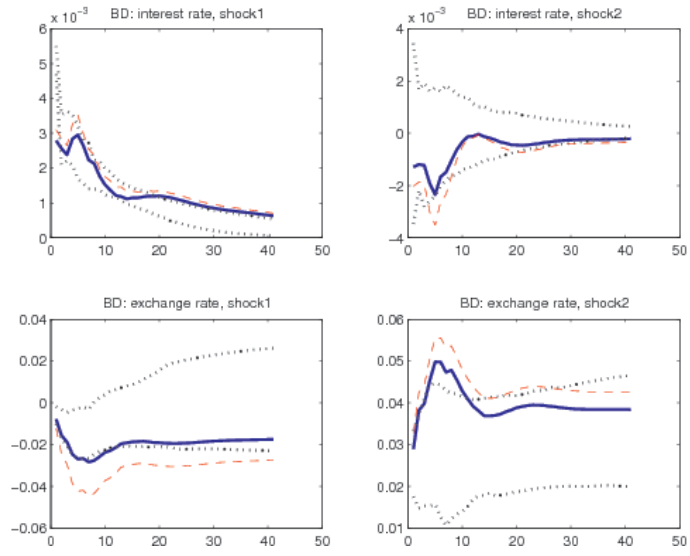

e) Japan
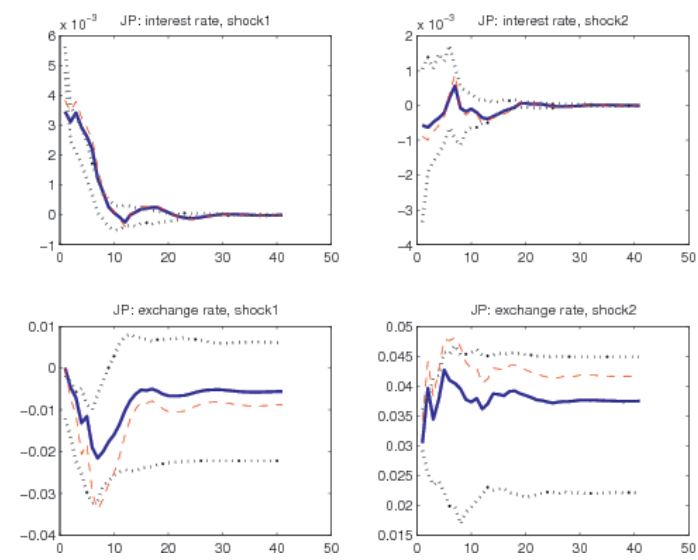

b) France
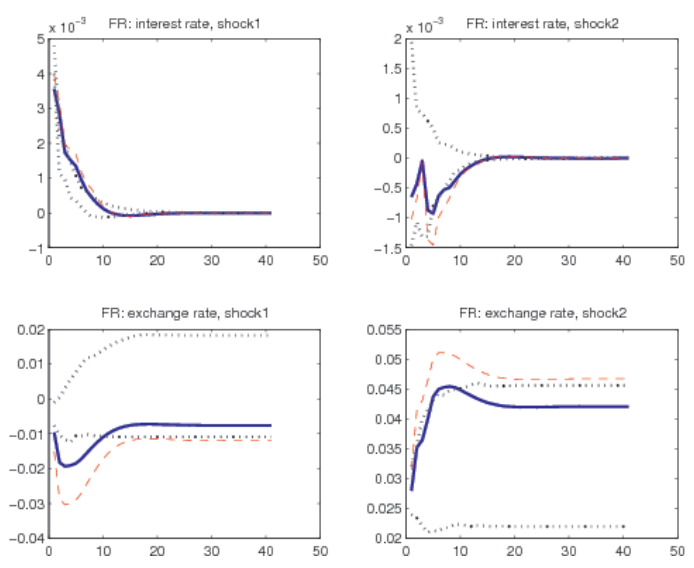

d) Italy
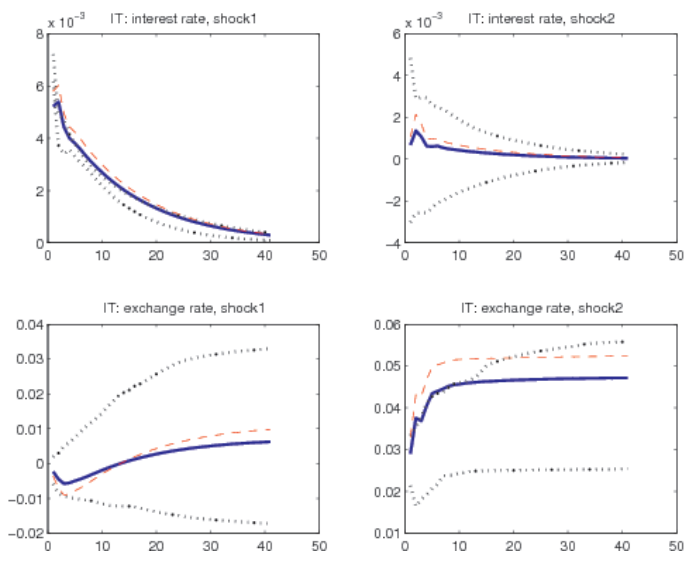

f) United Kingdom
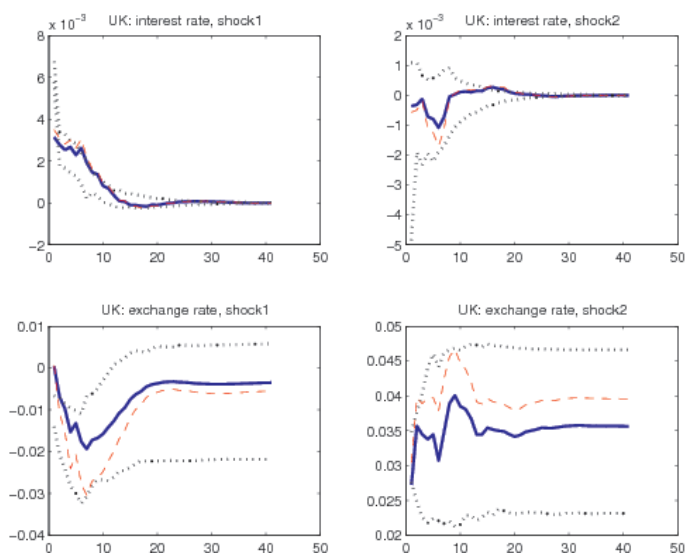

NOTES: Mean (blue, solid) and median (red, dashed) across all responses obtained from $P(\lambda)^{\prime} S_{C h o l}$ for $0<\lambda<2 \pi$. Black, dotted lines are $10 \%$ confidence intervals of the mean response obtained by 100 bootstrap replications. Sample period is 1978Q2 to $2007 \mathrm{Q} 3$ 